\title{
Labor market frictions, capital, taxes and employment
}

\author{
Kangoh Lee ${ }^{1}$
}

Accepted: 25 November 2020 / Published online: 4 January 2021

(c) The Author(s), under exclusive licence to Springer Science+Business Media, LLC part of Springer Nature 2021

\begin{abstract}
This paper studies the role of the tax on mobile capital in labor markets with matching frictions and the effects of such frictions on inefficiency of capital taxation. Firms acquire capital and create vacancies, and workers apply for firms. Due to matching frictions, vacancies may not be filled, and workers may not be employed. Firms' investment in capital, wages and market tightness are determined in a way that a firm's profit and a worker's utility are jointly maximized. In addition, the return to capital net of the tax is equalized across jurisdictions, as capital moves between jurisdictions. An increase in the capital tax of a jurisdiction alters firms' capital investment, wages and market tightness of the jurisdiction. In particular, it decreases employment and wages of the jurisdiction, providing an explanation for why policymakers of a jurisdiction provide incentives such as tax cuts for mobile capital. More capital increases the wages only when workers are employed and hence have higher incomes, decreasing the benefit of more capital for risk-averse workers and reducing the incentives of a jurisdiction to lower the tax and attract capital. The equilibrium capital tax thus may be too low or too high relative to the efficient level, and capital is taxed even with the head tax.
\end{abstract}

Keywords Matching frictions $\cdot$ Capital $\cdot$ Risk aversion $\cdot$ Employment $\cdot$ Taxes

JEL classification $\mathrm{H} 71 \cdot \mathrm{H} 73 \cdot \mathrm{J} 63 \cdot \mathrm{R} 12 \cdot \mathrm{R} 13$

I am grateful to Jan Brueckner, Priyaranjan Jha, two anonymous referees, and the seminar participants at Universidad Carlos III de Madrid and Universidad Autonoma de Madrid for their helpful comments.

Kangoh Lee

klee@sdsu.edu

1 Department of Economics, San Diego State University, 5500 Campanile Drive, San Diego, CA 92182-4485, USA 


\section{Introduction}

A large body of research has studied tax competition, and the literature is still growing. ${ }^{1}$ Tax competition is an important topic not only in academic research, but also in policy circles (Organization 1998, 2000; Gurria 2014), as jurisdictions tend to cut capital taxes in an inefficient manner in order to attract capital. Although a small literature has studied imperfect labor markets, as discussed below, much of the tax competition literature has naturally focused on capital, and labor markets rarely play any role in the analysis of tax competition. ${ }^{2}$ In particular, labor markets are typically assumed to be perfect, and no unemployment exists. However, this treatment of labor markets in much of the tax competition literature is unfortunate and unrealistic for two reasons.

First, unlike the classical labor market, labor markets in a real economy are characterized by unemployed workers and unfilled jobs (for example, Hall 2005; Shimer 2005; Diamond 2011). This observation has spurred a good deal of research on frictions in labor markets (McCall 1970; Diamond 1982; Mortensen 1982; Mortensen and Pissarides 1994; Moen 1997; Pissarides 2000; Rogerson et al. 2005). The basic idea of the literature is that workers search for jobs but are not necessarily employed due to frictions such as imperfect information about vacancies and the costs of applying for jobs. Likewise, firms post vacancies to hire workers, but vacancies are not necessarily filled again due to frictions such as the cost of hiring.

Second, the media and policymakers often mention tax incentives as a way of bringing jobs. In fact, states and cities have competed for capital and businesses to create jobs by providing incentives such as tax cuts. Using data on business taxes and business incentives for 47 US cities in 33 states for 45 industries during a period of 26 years, 1990-2015, Bartik (2017) estimates that the present value of business incentives in 2015 amounts to about $30 \%$ of average state and local business taxes for new or expanding businesses in industries that sell their products outside the local area. This leads to a projection of $\$ 45$ billion in 2015 for the entire nation. Other estimates of business incentives range from $\$ 65$ billion per year (Thomas 2011 ) to $\$ 90$ billion per year (Story 2012). An illuminating example is that US cities have recently promised a large sum of tax incentives exceeding billions of dollars to attract the Amazon Inc's second headquarter (Livengood 2018). At a national level, for example, Ireland has given tax breaks to attract multinationals (Dalby and Scott 2005), and the USA has recently cut corporate taxes in an attempt to bring jobs to the USA (Stevenson and Ewing 2017).

The discussion above motivates this research. In particular, this paper attempts to add to tax competition models in two ways. First, unemployment and imperfect

\footnotetext{
${ }^{1}$ For recent surveys, see, for example, Baskaran and Lopes da Fonseca (2013), Keen and Konrad (2013) and Karmakar and Martinez-Vazquez (2014).

2 For example, on November 1, 2019, Google Scholar search for 'tax competition, imperfect labor markets' since 2000 led to about $1.7 \%$ of the results of Google Scholar search for 'tax competition' since 2000 , and the percentage increased to $3.5 \%$ when searches were limited to since 2010. These numbers indicate that imperfect labor markets have been studied more in the tax competition literature since 2010, but still account for a small fraction of the literature.
} 
labor markets have been considered in tax competition models with fixed wages or labor unions. Labor unions play an important role in some industries and countries, but a majority of labor markets across economies are not unionized. A tax competition model of matching frictions in this paper thus provides a useful alternative to labor union settings. Beyond a different cause of unemployment, the matchingfriction approach provides a different explanation for the inefficiency of capital taxation. In a union model, wages do not equal the marginal product of labor, and more capital does not necessarily increase the wages and employment, so a jurisdiction that cares about wages and employment may undertax or overtax capital, depending on whether capital and labor are substitutes or complements. In this paper, labor markets are efficient despite frictions, and wages equal the marginal product. However, more capital benefits the wages only when workers are employed, and riskaverse workers value capital less than they would in perfect labor markets, reducing the incentives of a jurisdiction to undertax and attract capital. Second, the tax competition literature has mainly focused on inefficiency of capital taxes, an important economic question. This paper concerns the effects of capital taxes on employment and wages, a question that has interested policymakers, through comparative statics exercises, in addition to the inefficiency question.

In the model, the economy consists of two jurisdictions. Each jurisdiction has a continuum of identical residents (workers) and firms. Firms create vacancies and post wages by acquiring capital, and workers apply for jobs. A vacancy may not be filled, and a worker may not be employed. Once a match is formed and output is produced, the worker earns the wage, and the firm enjoys the profit. In a labor market equilibrium of a jurisdiction, firms' investment in capital, wages and market tightness (the ratio of the number of vacancies to the number of workers searching for jobs) are determined in a way that the utilities of workers and the profits of firms are maximized. In addition, capital moves between jurisdictions, and the return to capital net of the tax is equalized in the interjurisdictional (international) capital market equilibrium.

The analysis first considers comparative statics results concerning the effects of a change in an exogenous capital tax. A change in the capital tax of a jurisdiction alters firms' investment in capital, wages and market tightness of both jurisdictions. The analysis shows that an increase in the capital tax of a jurisdiction decreases firms' investment, employment and wages of the jurisdiction but increases the same variables of the other jurisdiction. This result thus provides a reason why policymakers of a jurisdiction provide incentives such as tax cuts for mobile capital, but the literature has studied mainly inefficiency of capital taxes and has rarely considered the comparative statics results.

The analysis turns to the inefficiency of capital taxes. The main proposition in the literature on tax competition states that the equilibrium capital tax chosen by self-interested jurisdictions is too low relative to the socially efficient level (Wilson 1986; Zodrow and Mieszkowski 1986; Wildasin 1989). The reason is that an increase in the capital tax of a jurisdiction moves capital to other jurisdictions and increases their tax revenues, but the jurisdiction does not consider this positive external benefit it confers on other jurisdictions. The exodus of capital to other jurisdictions also increases the wages and decreases the capital income (net return to 
capital) other jurisdictions enjoy, ${ }^{3}$ but they cancel out and have no efficiency consequence. With labor market frictions, the same exodus of capital increases the tax revenues of other jurisdictions and creates the traditional positive externality. However, the same exodus of capital increases the wages of workers in other jurisdictions only when they are employed, but decreases the capital income other jurisdictions enjoy regardless of whether workers are employed or unemployed. Since the income is higher when employed than when unemployed, and since workers are risk averse, the increase in the wage is valued less than the decrease in the capital income, so an increase in the capital tax of a jurisdiction imposes a new negative externality on other jurisdictions. This negative externality may or may not outweigh the positive externality, and the equilibrium capital tax may be too high or too low relative to the efficient one. Risk aversion is thus crucial to inefficiency of capital taxation and possible overtaxation of capital, but to the best of my knowledge, risk aversion has not been considered in the studies of inefficient capital taxes. In addition, even with the head tax, capital is taxed in equilibrium, unlike in the standard model in which the head tax obviates the need for the capital tax. The reason is that frictions and possible unemployment lower the cost of taxing capital arising from capital flight and lower wages. A jurisdiction is thus willing to tax capital more than in perfect labor markets.

Risk aversion plays an important role in the inefficiency of capital tax competition in this paper, but the role of risk aversion may be relevant to other settings. Most countries have implemented active labor market policies. Job training for lowskilled workers increases their basic skills, and it mainly increases the productivity or wage although it also increases the employability (McKenzie 2017; Attanasio et al. 2011). The utility benefit of training for low-skilled workers thus may be limited, as low-skilled workers are known to be more risk averse (Swanson 2020), and the wage gain from training is realized only when workers are employed and have higher incomes. Job search assistance programs aim to directly increase employment (Graversen and Van Ours 2008; Gautier et al. 2018), providing a more direct utility benefit than training. As another example, the Earned Income Tax Credit has been advocated, as it encourages the recipients to work, unlike cash transfers (Meyer and Rosenbaum 2001; Bastian 2020). However, the recipients enjoy the benefits of the Earned Income Tax Credit only when they are employed and have higher incomes, so the utility benefit for risk-averse workers would be smaller. A universal basic income is provided regardless of the employment status and suffers less from the utility effect associated with risk aversion. Incidentally, universal basic incomes have recently received attention (Daruich and Fernández 2020) although risk aversion has not been a factor in the literature or policy debates.

Tax competition has received a good deal of attention (Wilson 1986; Zodrow and Mieszkowski 1986; Wildasin 1989; Brueckner 2000; survey papers noted earlier). This paper considers tax competition in labor markets with matching frictions, and

\footnotetext{
3 The wage increases due to the complementarity between labor and capital when the production function exhibits constant returns to scale, but the capital income decreases due to the diminishing returns to capital.
} 
it is relevant to relate this paper to tax competition models with imperfect labor markets or unemployment. Like this paper, a number of papers model matching frictions. Boadway et al. $(2002 ; 2004)$ consider a matching model to study jurisdictional policies in the presence of unemployment. In their models, no capital exists and labor is the only input, and their main goal is to characterize government policies to achieve efficiency. Their models thus are not directly related to tax competition models that study inefficiency of capital taxes. Sato (2009) considers a matching model, and studies the inefficiency of capital taxation in the presence of inefficient labor markets due to matching externalities. Matching externalities play a key role in explaining inefficiency of capital taxes in Sato (2009). In this paper, labor markets are efficient despite frictions, and no matching externalities exist due to wage posting (Moen 1997; Acemoglu and Shimer 1999; Rogerson et al. 2005). Inefficiency of tax competition in this paper is driven by risk aversion and partial benefits of capital on the wages due to possible unemployment, as discussed above. Hungerbühler and Ypersele (2014) consider matching frictions and study the role of labor market efficiency in determining capital taxes. In their result with symmetric jurisdictions, tax competition is efficient, as no public good exists and no tax is imposed in equilibrium in their model. As the public good is essential to inefficiency of tax competition with symmetric jurisdictions, their paper is not directly related to this paper.

Unemployment also occurs due to fixed wages or labor unions. Ogawa et al. (2006) consider a fixed wage to generate unemployment and show that the capital tax by a jurisdiction may be too high or too low relative to the efficient level if capital and labor are substitutes (complements) unlike in the standard model. ${ }^{4}$ The reason for possibly too high a tax is that a jurisdiction desires to increase employment and hence to decrease capital by overtaxing capital when labor and capital are substitutes. Eichner and Upmann $(2012,2014)$ add labor market institutions, such as efficient Nash bargains and the monopolistic labor union, to the fixed-wage model to explain how unemployment occurs. In their model, assuming efficient Nash bargains, tax competition leads to either overprovision or underprovision of public goods (too high or too low a capital tax relative to the efficient level), depending mainly on whether labor and capital are complements or substitutes, as in the fixed-wage model. ${ }^{5}$ In this paper, inefficiency of the capital tax or the direction of inefficiency (too high or too low a capital tax) does not depend on the relationship

\footnotetext{
${ }^{4}$ Lozachmeur (2003) considers the effect of fiscal competition on unemployment benefits in a model with a minimum wage, and shows that competition results in an underprovision of unemployment benefits. Moriconi and Sato (2009) analyze the effects of international commodity taxation on employment when unemployment occurs due to a minimum wage. These papers consider fixed wages but not capital or capital taxes, so are not directly related to capital tax competition.

${ }^{5}$ A good number of papers study tax competition in labor union models, but do not consider capital or public good provision or inefficiency of capital taxes, so they are not directly related to this paper. For instance, Lejour and Verbon (1996) study the effects of fiscal competition on the provision of social insurance, Lorz and Stähler (2001) consider the effect of capital mobility on the public sector size, and Leite-Monteiro et al. (2003) analyze the effects of tax competition on median voter's choice of employment subsidy. Aronsson and Wehke (2008) demonstrate that tax coordination among jurisdictions is welfare improving, and Wehke (2008) studies the difference between the welfare effect of full tax coordination and that of partial tax coordination in the presence of labor unions and unemployment. Exbrayat et al. (2012) find that capital taxes increase in the country with less rigid labor markets when both markets shift from a competitive market to a unionized market, but do not consider public goods.
} 
between capital and labor, but again is driven by risk aversion and partial benefits of capital on the wages, as noted above. In general, the key difference between fixedwage or union models and this paper lies in the way that unemployment occurs and labor market outcomes are determined. In the standard models with competitive labor markets and no unemployment, the wage equals the marginal product of labor and increases in capital, while the return to capital equals the marginal product of capital and decreases in capital due to two-factor constant-returns-to-scale production functions, so a decrease in the capital tax of a jurisdiction attracts capital and increases the wage but decreases the capital income of the jurisdiction. The same is true in this paper, as labor markets are still competitive and efficient despite frictions and unemployment (Moen 1997; Acemoglu and Shimer 1999; Rogerson et al. 2005). However, the beneficial effect of capital on the wage occurs only when workers are employed. This partial effect of capital on the wage, along with risk aversion, reduces the incentive of a jurisdiction to lower the tax and attract capital, because workers enjoy higher incomes when employed and hence the utility gain of the increase in the wage is valued less to risk-averse workers. In the fixed-wage model or the union model, the wage does not equal the marginal product of labor due to the way unemployment is generated. In addition, the fixed-wage or the union model does not assume the two-factor constant-returns-to-scale production function, under which labor and capital are complements. Thus, more capital does not necessarily increase the wage and employment that a jurisdiction cares about, and the incentive of the jurisdiction to undertax or overtax capital depends in general on the shape of the production function or the relationship between capital and labor.

The next section describes a simple model. Section 3 studies the labor and capital markets. Section 4 analyzes the effects of a change in an exogenous capital tax on employment and wages. Section 5 considers the inefficiency of capital taxes. Section 6 considers the capital taxes with head taxes, and the last section concludes.

\section{Model}

A simple model is considered to study the role of capital taxes in labor market outcomes and the effects of labor market frictions on inefficiency of capital taxation. To that end, this section borrows the setup from tax competition models (Wilson 1986; Zodrow and Mieszkowski 1986; Wildasin 1989) and from search models (Acemoglu and Shimer 1999; Rogerson et al. 2005). The key difference from search models is that capital moves between jurisdictions and the allocation of capital is determined in the (international/interjurisdictional) capital market, as in tax competition models. ${ }^{6}$

The economy consists of two jurisdictions, indexed by subscripts $i=1,2$. Each jurisdiction has a continuum of identical residents with the number of residents normalized to one. Firms combine capital and labor to produce output that serves as a numeraire. Capital is mobile between jurisdictions, but labor is immobile. There are thus two labor markets, one for each jurisdiction, and one capital market.

\footnotetext{
${ }^{6}$ Capital, not to mention the mobility of capital, is usually not considered in matching models.
} 
While the model is static, decisions are made in sequence and the timing of events is postulated as follows. The government of jurisdiction $i$ chooses the capital tax $t_{i}, i=1,2$. Capital $k$ moves between jurisdictions to maximize its return net of the taxes. Each firm of a jurisdiction acquires capital, and creates a vacancy and posts a wage. Observing wages, each worker of the jurisdiction decides which firm to apply for. A worker is employed with some probability, and a vacancy is filled with some probability. A worker's utility and a firm's profit are realized.

\section{Labor markets and capital market}

This paper adopts a competitive search model in order to focus on inefficiency of tax competition in the presence of search frictions. It is thus useful to briefly explain the structure of a competitive search model although the model is formally analyzed below, as the structure of a competitive search model is somewhat different from the structure of a well-known Mortensen-Pissarides type search model. In a competitive search model, firms post wages, and workers apply for jobs. Workers' arbitrage ensures that the job searcher's asset value is the same for those applying to jobs with the same wage rate. Given the job searcher's asset value, each firm then anticipates the job searchers' queue (and hence the market tightness) when posting the wage rate. Free entry and exit of firms drive the asset value of posting a vacancy to zero. Workers' arbitrage, firms' wage posting, and free entry determine the job searcher's asset value, the wage rate, and the market tightness.

Residents/workers and firms of jurisdiction $i$ attempt to form productive matches to produce output. The approach to matching here follows Acemoglu and Shimer (1999) and Rogerson et al. (2005). Firm $h$ of jurisdiction $i$ acquires $k_{i}^{h}$ units of capital, and creates a vacancy and posts a wage $w_{i}^{h}, i=1,2$. That is, capital investment $k$ is irreversible (Acemoglu 1996; Acemoglu and Shimer 1999, 2000; Rogerson et al. 2005). Observing wages, a worker of the jurisdiction decides which firm to apply for. Multiple firms may post a same wage $w_{i}^{h}$, and multiple workers may apply for a firm. Let $\theta_{i}^{h}$ denote the ratio of the number of firms posting $w_{i}^{h}$ to the number of workers applying for firms posting $w_{i}^{h}$, called the firms' expected tightness. A worker applying for a firm posting a wage $w_{i}^{h}$ is assumed to be hired with probability $\mu_{i}\left(\theta_{i}^{h}\right)$, and a firm posting a wage $w_{i}^{h}$ is assumed to fill the vacancy with probability $\eta_{i}\left(\theta_{i}^{h}\right)$. As is standard in the matching literature, this formulation of $\mu_{i}\left(\theta_{i}^{h}\right)$ and $\eta_{i}\left(\theta_{i}^{h}\right)$ assumes constant returns to scale in matching, so that matching outcomes depend only on tightness, not on the number of workers or vacancies. As a firm's tightness increases or fewer workers apply for the firm, the probability of a worker being employed increases and the probability of a vacancy being filled decreases, so that

$$
\mu_{i}^{\prime}\left(\theta_{i}^{h}\right)>0, \text { and } \eta_{i}^{\prime}\left(\theta_{i}^{h}\right)<0 \text {. }
$$

When a match between a firm posting $w_{i}^{h}$ and a worker is created, the worker supplies one unit of labor inelastically. Using one unit of labor and $k_{i}^{h}$ units of capital, the firm produces output $f_{i}\left(k_{i}^{h}\right)$, an increasing and concave production function. In that event, the worker earns the wage $w_{i}^{h}$, and the firm enjoys $f_{i}\left(k_{i}^{h}\right)-w_{i}^{h}$. When no 
match is created, no output is produced, and a worker receives no wage and a firm enjoys no profit. Regardless of whether a worker is employed or unemployed, she is endowed with capital $\bar{K}_{i}$ and earns capital income $\rho \bar{K}_{i}$ with $\rho$ denoting the return to capital net of the capital tax to be determined in the capital market, ${ }^{7}$ and enjoys the public good $z_{i}{ }^{8} z_{i}$ is financed by a capital tax $t_{i}$. The expected utility of a worker applying for a firm posting a wage $w_{i}^{h}$ reads as

$$
U_{i}^{h}=\mu_{i}\left(\theta_{i}^{h}\right) u_{i}\left(w_{i}^{h}+\rho \bar{K}_{i}\right)+\left(1-\mu_{i}\left(\theta_{i}^{h}\right)\right) u_{i}\left(\rho \bar{K}_{i}\right)+v_{i}\left(z_{i}\right) .
$$

The first two terms represent the expected utility of private good consumption, the labor and capital incomes, with $u_{i}^{\prime}()>$.0 and $u_{i}^{\prime \prime}()<.0 .{ }^{9}$ The last term is the utility of the public good with $v_{i}^{\prime}>0$ and $v_{i}^{\prime \prime}<0$. Unemployment insurance could be introduced, but it has no effect on the role of capital, the focus of this paper, and will be ignored. ${ }^{10}$

A firm posting a wage $w_{i}^{h}$ enjoys the expected profit

$$
\pi_{i}^{h}=-r_{i} k_{i}^{h}+\eta_{i}\left(\theta_{i}^{h}\right)\left[f_{i}\left(k_{i}^{h}\right)-w_{i}^{h}\right],
$$

where $r_{i}$ is the gross price of capital. Unlike the wage $w_{i}^{h}$, the price of capital $r_{i}$ is not firm-specific, as any firm can purchase any amount of capital in the interjurisdictional (international) capital market. However, the gross price of capital $r_{i}$ includes a capital tax and is jurisdiction-specific although the net return to capital $\rho$, the capital price net of the tax, will be equalized across jurisdictions in the capital market equilibrium.

Let $\bar{u}_{i}$ denote the highest expected utility a worker can enjoy by applying for a firm of jurisdiction $i . \bar{u}_{i}$ is endogenously determined in a labor market equilibrium, but firms and workers take $\bar{u}_{i}$ as given when firms post a wage and workers apply for a firm. A worker is willing to apply for a firm posting a wage $w_{i}^{h}$ only if $U_{i}^{h} \geq \bar{u}_{i}$. In equilibrium, the constraint is binding and $U_{i}^{h}=\bar{u}_{i}$, because otherwise the firm will not be able to attract job applicants and $\theta_{i}^{h}$ and hence $\mu_{i}\left(\theta_{i}^{h}\right)$ will increase, increasing $U_{i}^{h}$ and equating $U_{i}^{h}$ with $\bar{u}_{i}$. In equilibrium, all firms of jurisdiction $i$ post the same wage $w_{i}$ that leads to $\bar{u}_{i}$, resulting in the same $\theta_{i}$ and hence $k_{i}$, so

$$
U_{i}=\mu_{i}\left(\theta_{i}\right) u_{i}\left(w_{i}+\rho \bar{K}_{i}\right)+\left(1-\mu_{i}\left(\theta_{i}\right)\right) u_{i}\left(\rho \bar{K}_{i}\right)+v_{i}\left(z_{i}\right)=\bar{u}_{i} .
$$

(1) defines implicitly $\theta_{i}$ as a function of $w_{i}$. To find the relationship between $w_{i}$ and $\theta_{i},(1)$ is differentiated with respect to $w_{i}$ and $\theta_{i}$, taking $\bar{u}_{i}$ as given, as noted above, to obtain

\footnotetext{
7 The net return $\rho$ depends on the capital tax of a jurisdiction and should be written as $\rho_{i}$. As a capital owner invests in either jurisdiction, the net return to the owner of jurisdiction 1 equals $\rho_{1} \bar{K}_{11}+\rho_{2} \bar{K}_{12}$ with $\bar{K}_{11}$ and $\bar{K}_{12}$ denoting capital invested in jurisdiction 1 and jurisdiction 2 , respectively. To simplify notation, $\rho_{1} \bar{K}_{11}+\rho_{2} \bar{K}_{12}$ is written as $\rho \bar{K}_{11}+\rho \bar{K}_{12}=\rho \bar{K}_{1}$, as $\rho_{1}=\rho_{2}$ in equilibrium.

8 As will be discussed below, free entry results in zero profits, and ownership of firms does not matter.

9 Workers may also enjoy home production when unemployed, but the inclusion of home production turns out to play no role qualitatively in the subsequent analysis, and it will be henceforth ignored for simplicity.

10 An earlier version of this paper included unemployment insurance.
} 


$$
\frac{\partial \theta_{i}}{\partial w_{i}}=-\frac{\mu_{i} u_{i e}^{\prime}}{\mu_{i}^{\prime}\left[u_{i e}-u_{i u}\right]}<0,
$$

where $\theta_{i}$ is dropped in $\mu_{i}\left(\theta_{i}\right)$ and $\eta_{i}\left(\theta_{i}\right), u_{i e} \equiv u_{i}\left(w_{i}+\rho \bar{K}_{i}\right)$ and $u_{i u}=u\left(\rho \bar{K}_{i}\right)$, and similarly for $u_{i e}^{\prime}$ with subscripts $e$ and $u$ denoting employment and unemployment, respectively. (1) and (2) are the constraints that workers and firms face in the labor market. The probability of a worker finding a higher-wage job is lower than that of a lower-wage job, as a higher wage decreases tightness $\theta$ in (2) and hence decreases the job finding rate $\mu(\theta)$. Likewise, the probability of hiring a worker by a lowerwage offering firm is lower than that by a higher-wage offering firm, as a lower wage increases tightness $\theta$ in (2) and hence decreases the vacancy filling rate $\eta(\theta)$.

A firm chooses $k_{i}$ and $w_{i}$ to maximize its profit $\pi_{i}$ subject to (2), and the FOCs (firstorder conditions) are

$$
\begin{gathered}
\frac{\partial \pi_{i}}{\partial k_{i}}=-r_{i}+\eta_{i} f_{i}^{\prime}=0 \\
\frac{\partial \pi_{i}}{\partial w_{i}}=-\eta_{i}^{\prime} \frac{\mu_{i} u_{i e}^{\prime}}{\mu_{i}^{\prime}\left[u_{i e}-u_{i u}\right]}\left[f_{i}\left(k_{i}\right)-w_{i}\right]-\eta_{i}=0 .
\end{gathered}
$$

Free entry of firms results in zero profits, and

$$
\pi_{i}=-r_{i} k_{i}+\eta_{i}\left[f_{i}-w_{i}\right]=0 .
$$

Substitution of (3) into (5) gives

$$
w_{i}=f_{i}\left(k_{i}\right)-k_{i} f_{i}^{\prime} .
$$

Substitution of (6) into (4) yields

$$
\begin{aligned}
& \eta_{i} \mu_{i}^{\prime}\left[u_{i}\left(f_{i}-k_{i} f_{i}^{\prime}+\rho \bar{K}_{i}\right)-u_{i}\left(\rho \bar{K}_{i}\right)\right] \\
& \quad+\eta_{i}^{\prime} k_{i} f_{i}^{\prime} \mu_{i} u_{i}^{\prime}\left(f_{i}-k_{i} f_{i}^{\prime}+\rho \bar{K}_{i}\right)=0 .
\end{aligned}
$$

(7) is the key equation, and it is worthwhile to discuss an alternative approach to (7). Firms chose $k_{i}$ and $w_{i}$ to maximize profits subject to the labor market constraints in (1) and (2), which, along with the free-entry condition, led to (7). This approach was taken by Rogerson et al. (2005) in their survey article and has been widely used in the search literature. Alternatively, the utility of a worker can be maximized by choosing $w_{i}, k_{i}$ and $\theta_{i}$ subject to the free-entry condition. That is, $\left(w_{i}, k_{i}, \theta_{i}, \lambda\right)$ is chosen to maximize

$$
\begin{aligned}
& \mu_{i}\left(\theta_{i}\right) u_{i}\left(w_{i}+\rho \bar{K}_{i}\right)+\left(1-\mu_{i}\left(\theta_{i}\right)\right) u_{i}\left(\rho \bar{K}_{i}\right)+v_{i}\left(z_{i}\right) \\
& \quad+\lambda\left[-r_{i} k_{i}+\eta_{i}\left(\theta_{i}\right)\left(f_{i}\left(k_{i}\right)-w_{i}\right)\right]
\end{aligned}
$$


where $\lambda$ is a multiplier. It is straightforward to verify that four FOCs result in (3) through (6) and hence lead to (7). This was the approach taken by Acemoglu and Shimer (Proposition 1, 1999).

In the second line of (7), $k_{i} f_{i}^{\prime}=f_{i}-w_{i}$, so $k_{i} f_{i}^{\prime}$ is considered (operating) profit after capital $k_{i}$ is sunk. Since an increase in $\theta_{i}$ decreases the probability of a vacancy being filled by $-\eta^{\prime}$ and hence that of a firm enjoying a profit by $-\eta_{i}^{\prime}$, the second line of (7) is the loss of expected profit resulting from an increase in $\theta_{i} \cdot{ }^{11}$ Since an increase in $\theta_{i}$ increases the probability of a worker being employed and hence that of a worker enjoying the utility of a wage plus non-wage income over the utility of non-wage income only, the first line of (7), $\mu_{i}^{\prime}\left(u_{i e}-u_{i u}\right)$, is the gain of expected utility resulting from an increase in $\theta_{i}$. Condition (7) then states that in equilibrium, the marginal expected utility (a change in the expected utility resulting from a change in $\theta_{i}$ ) of a worker equals the marginal expected profit of a firm.

(6) shows that the wage equals the marginal product of labor. In general, labor markets are still efficient despite matching frictions and unemployment (Moen 1997; Acemoglu and Shimer 1999; Rogerson et al. 2005). To simplify (7), observe that by the definition of $\mu(\theta)$ and $\eta(\theta), \mu(\theta)=\theta \eta(\theta) .{ }^{12}$ Differentiation of the last equality results in

$$
\mu_{i}^{\prime}\left(\theta_{i}\right)=\eta_{i}\left(\theta_{i}\right)+\theta_{i} \eta_{i}^{\prime}\left(\theta_{i}\right)=\eta_{i}\left(\theta_{i}\right)\left[1-\epsilon_{i}\left(\theta_{i}\right)\right],
$$

where

$$
\epsilon_{i}\left(\theta_{i}\right) \equiv \frac{-\theta_{i} \eta_{i}^{\prime}\left(\theta_{i}\right)}{\eta_{i}\left(\theta_{i}\right)}>0
$$

denotes the elasticity of the vacancy-filling rate, $\eta_{i}\left(\theta_{i}\right)$, with respect to market tightness $\theta_{i}$. Substituting (8), along with $\mu(\theta)=\theta \eta(\theta)$, into (7),

$$
\begin{gathered}
\left(1-\epsilon_{i}\right)\left[u_{i}\left(f_{i}-k_{i} f_{i}^{\prime}+\rho \bar{K}_{i}\right)-u_{i}\left(\rho \bar{K}_{i}\right)\right] \\
-\epsilon_{i} u_{i}^{\prime}\left(f_{i}-k_{i} f_{i}^{\prime}+\rho \bar{K}_{i}\right) k_{i} f_{i}^{\prime}=0 .
\end{gathered}
$$

As noted above, this paper is based on a wage-posting model, rather than a wagebargaining model (Mortensen 1982; Pissarides 2000). The latter has been more popular in the studies of labor market frictions perhaps because it was developed earlier. Two models differ mainly in two respects. The bargaining model assumes that a worker and a firm meet randomly and divide the surplus from production via Nash bargaining. The bargaining outcome depends on the magnitude of a parameter that measures the bargaining power of each party, but the parameter is exogenous. The wage-posting model assumes that firms post wage offers and workers direct their search to the utility-maximizing offers. The model determines the wages and profits

\footnotetext{
11 The remaining term, namely $\mu_{i} u_{i e}^{\prime}$, is the weight placed on the profit of a firm when both the utility of a worker and the profit of a firm are maximized. Likewise, $\eta_{i}$ in the first line is the weight placed on the utility of a worker.

12 Let a matching function $M(x, b)$ represent the number of matches that are formed between $x$ workers and $b$ firms, so that $\mu(\theta)=M(x, b) / x$ and $\eta(\theta)=M(x, b) / b$. As $\theta=b / x, \mu(\theta)=\theta \eta(\theta)$.
} 
endogenously by maximizing both a worker's utility and a firm's profit. However, the wage-posting model creates a commitment problem, as a worker and/or a firm may not have an incentive to honor the wage, after they meet, that a firm posted and a worker observed. This paper adopts the wage-posting model, because labor markets are competitive and efficient under the wage-posting model despite frictions, enabling the analysis to focus on the inefficiency of tax competition. By contrast, labor markets tend to be inefficient under the bargaining model, as bargaining creates externalities.

To close the model, letting $b_{i}$ and $x_{i}$ denote the number of vacancies firms create and the number of workers who search for jobs, respectively, the market tightness equals

$$
\theta_{i}=\frac{b_{i}}{x_{i}}=b_{i},
$$

as a unit mass of all residents are assumed to search and $x_{i}=1$. Each firm creates a vacancy, and there are $b_{i}$ firms, so the sum of firms' capital investment $k_{i}$ over $b_{i}$ firms in jurisdiction $i$ equals $b_{i} k_{i}=\theta_{i} k_{i}$. This demand for capital $k_{i}$ by firms of both jurisdictions must equal the supply of capital to the economy, $\bar{K}_{1}+\bar{K}_{2}$, so

$$
\theta_{1} k_{1}+\theta_{2} k_{2}=\bar{K}_{1}+\bar{K}_{2} \text {. }
$$

In addition, capital moves freely between jurisdictions, and the return to capital net of the capital tax $t_{i}$, the net return $\rho$, should be equalized between jurisdictions, and

$$
\rho=r_{i}-t_{i}=\eta_{i}\left(\theta_{i}\right) f_{i}^{\prime}\left(k_{i}\right)-t_{i}, i=1,2,
$$

where $r_{i}=\eta_{i}\left(\theta_{i}\right) f_{i}^{\prime}\left(k_{i}\right)$ from (3).

Two comments on condition (11) are in order. First, the condition assumes that capital taxes are paid by capital owners, as in the literature. Firms may pay profit taxes from their production activities, but this paper assumes profits are zero. However, since production by firms requires capital and capital moves in response to the tax incentives, tax policies to attract capital may be viewed as tax policies to attract firms, as in Introduction. For this reason, a capital tax and a corporate tax are sometimes used interchangeably (Peralta and Van Ypersele 2006). Second, as in much of the literature, the condition assumes that taxes are imposed on a source basis rather than on a residence basis. That is, the tax is paid to the jurisdiction where capital is located regardless of the residence of capital owners. A residence-based tax has been less studied in the literature perhaps because it is difficult to enforce a residence-based tax due to the mobility of capital and a residence-based tax is typically imposed on household savings and requires a two-period model, making the analysis more complicated (Fuest et al. 2005; Keen and Konrad 2013). Tax competition with a residence-based tax is an important issue, but such a tax with labor market frictions is beyond the scope of this paper and left for future research.

Four conditions in (9) and (11) for $i=1$ and $i=2$, along with (10), determine five variables, $\left(\theta_{1}, \theta_{2}, k_{1}, k_{2}, \rho\right)$ as functions of the taxes $\left(t_{1}, t_{2}\right)$. The taxes are 
treated as exogenous parameters in this section and the next section for the reason mentioned in the Introduction although they will be endogenously determined in Sect. 5. The next section discusses comparative statics concerning the effects of a change in an exogenous capital tax on the variables, $\left(\theta_{1}, \theta_{2}, k_{1}, k_{2}, \rho\right)$.

\section{Effects of a change in an exogenous capital tax on employment and wages}

Total differentiation of (9) through (11) gives

$$
\begin{aligned}
\frac{\partial \theta_{i}}{\partial t_{i}} & =-\frac{1}{D} A_{i k}\left[k_{j} A_{j k}-\theta_{j} A_{j \theta}\right], \\
\frac{\partial \theta_{j}}{\partial t_{i}} & =\frac{1}{D} A_{j k}\left[k_{i} A_{i k}-\theta_{i} A_{i \theta}\right], \\
\frac{\partial k_{i}}{\partial t_{i}} & =\frac{1}{D} A_{i \theta}\left[k_{j} A_{j k}-\theta_{j} A_{j \theta}\right], \\
\frac{\partial k_{j}}{\partial t_{i}} & =-\frac{1}{D} A_{j \theta}\left[k_{i} A_{i k}-\theta_{i} A_{i \theta}\right], \\
\frac{\partial \rho}{\partial t_{i}} & =-\frac{1}{D}\left[A_{j \theta} \eta_{j} f_{j}^{\prime \prime}-A_{j k} \eta_{j}^{\prime} f_{j}^{\prime}\right]\left[k_{i} A_{i k}-\theta_{i} A_{i \theta}\right], i \neq j, i, j=1,2,
\end{aligned}
$$

where

$$
\begin{aligned}
D \equiv & \left(A_{1 \theta} \eta_{1} f_{1}^{\prime \prime}-A_{1 k} n_{1}^{\prime} f_{1}^{\prime}\right)\left(k_{2} A_{2 k}-\theta_{2} A_{2 \theta}\right) \\
+ & \left(A_{2 \theta} \eta_{2} f_{2}^{\prime \prime}-A_{2 k} n_{2}^{\prime} f_{2}^{\prime}\right)\left(k_{1} A_{1 k}-\theta_{1} A_{1 \theta}\right), \\
A_{i} \equiv & \left(1-\epsilon_{i}\right)\left[u_{i}\left(f_{i}-k_{i} f_{i}^{\prime}+\rho \bar{K}_{i}\right)-u_{i}\left(\rho \bar{K}_{i}\right)\right] \\
& -\epsilon_{i} u_{i}^{\prime}\left(f_{i}-k_{i} f_{i}^{\prime}+\rho \bar{K}_{i}\right) k_{i} f_{i}^{\prime}, \\
A_{i k} \equiv & \frac{\partial A_{i}}{\partial k_{i}}=\left[\left(1-\epsilon_{i}\right) u_{i e}^{\prime}-\epsilon_{i} u_{i e}^{\prime \prime} k_{i} f_{i}^{\prime}\right]\left(-k_{i} f_{i}^{\prime \prime}\right) \\
& -\epsilon_{i} u_{i e}^{\prime}\left(f_{i}^{\prime}+k_{i} f_{i}^{\prime \prime}\right), \\
A_{i \theta} \equiv & \frac{\partial A_{i}}{\partial \theta_{i}}=-\epsilon_{i}^{\prime}\left[u_{i e}-u_{i u}+u_{i e}^{\prime} k_{i} f_{i}^{\prime}\right], i=1,2 .
\end{aligned}
$$

Note that $A_{i}$ is the LHS of (9).

The sign of $D$ in (13) is in general ambiguous, but $D$ can be signed using a stability condition. ${ }^{13}$ That is, for the comparative statics results in (12) to be stable, it must

\footnotetext{
${ }^{13}$ The difference between the LHS and the RHS of (10) can be interpreted as the excess demand for capital, $E \equiv \theta_{1} k_{1}+\theta_{2} k_{2}-\bar{K}_{1}-\bar{K}_{2}$. An increase in $k_{i}$ should decrease $E$ in equilibrium, so $d E / d k_{i}=\theta_{i}+k_{i}\left(\partial \theta_{i} / \partial k_{i}\right)=\theta_{i}-k_{i}\left(A_{i k} / A_{i \theta}\right)<0$. The inequality is satisfied if (16) holds and hence $D>0$, as explained in (16).
} 
be that $D>0$. However, the subsequent analysis considers sufficient conditions for $D>0$. To that end, observe that since $u_{i e}-u_{i u}=u_{i}\left(f_{i}-k_{i} f_{i}^{\prime}+\rho \bar{K}_{i}\right)-u\left(\rho \bar{K}_{i}\right)>0$,

$$
A_{i \theta}<(=,>) 0 \text { as } \epsilon_{i}^{\prime}>(=,<) 0 \text {. }
$$

In addition, letting

$$
\phi_{i} \equiv-\frac{k_{i} f_{i}^{\prime \prime}}{f_{i}^{\prime}}
$$

denote the elasticity of the marginal product of capital, simple calculation can show that $A_{i k}$ reduces to

$$
A_{i k}=u_{i e}^{\prime}\left(\phi_{i}-\epsilon_{i}\right) f_{i}^{\prime}-\epsilon_{i} u_{i e}^{\prime \prime} \phi_{i} k_{i}\left(f_{i}^{\prime}\right)^{2} .
$$

Thus, $A_{i k}>0$ if $\phi_{i} \geq \epsilon_{i}$. As a result, $D>0$ if

$$
\epsilon_{i}^{\prime} \geq 0 \text { and } \phi_{i} \geq \epsilon_{i}
$$

because then $A_{i \theta} \leq 0$ and $A_{i k}>0$, so $k_{i} A_{i k}-\theta_{i} A_{i \theta}>0$ and the remaining terms are all positive. Otherwise, $D$ cannot be signed.

With the conditions in (16), all comparative statics results in (12) can be unambiguously signed. The following result can then be stated:

Proposition 1 Assume (16). $\partial \theta_{i} / \partial t_{i}<0, \partial k_{i} / \partial t_{i}<0, \partial \theta_{j} / \partial t_{i}>0$, and $\partial k_{j} / \partial t_{i}>0$ (an increase in the capital tax of a jurisdiction decreases employment and capital investment of the jurisdiction but increases employment and capital investment of the other jurisdiction).

To have a sense of the plausibility of the conditions in the proposition, consider the production function $f(k)=k^{\alpha}$ with $\alpha \in(0,1)$. In this case, $\phi=-k f^{\prime \prime} / f^{\prime}=\alpha(1-\alpha) k^{(\alpha-1)} / \alpha k^{(\alpha-1)}=1-\alpha$. Since $\alpha$ can be interpreted as the capital share of output, it is about $1 / 3=0.33$, so $\phi=1-0.33=0.67$. Empirical estimates of $\epsilon$ are known to be about 0.24 (Hall 2005). ${ }^{14}$ Thus, the condition, $\phi>\epsilon$, appears reasonable. If $f(k)=\alpha k-k^{2}, \phi=2 k /(\alpha-2 k)$. Letting $\omega \equiv\left(f-k f^{\prime}\right) / f=k /(\alpha-k)$ denote the labor (wage) share of output, $\phi$ can be expressed as $\phi=2 \omega /(1-\omega)$, which exceeds the estimate value 0.24 of $\epsilon$ for reasonable values of $\omega$. For instance, if $\omega=2 / 3, \phi=4$. As for the second condition, if $\mu(\theta)=1-e^{-\theta}$ and $\eta(\theta)=\left(1-e^{-\theta}\right) / \theta$, as in Acemoglu and Shimer (1999), it can be shown that $\epsilon=1-\left[\theta e^{-\theta} /\left(1-e^{-\theta}\right)\right]$ and the sign of $\epsilon^{\prime}$ is the same as that of $\left(\theta-1+e^{-\theta}\right)$, which is positive. ${ }^{15}$ The second condition, $\epsilon^{\prime} \geq 0$, thus also appears reasonable. For the remainder of the paper, the conditions in (16) will be assumed.

\footnotetext{
${ }^{14}$ Hall (2005) estimates that the elasticity of the job-finding rate with respect to market tightness, $\theta \mu^{\prime} / \mu=\left[\theta\left(\eta+\theta \eta^{\prime}\right)\right] / \mu=1+\left(\theta \eta^{\prime} / \eta\right)=1-\epsilon$, equals 0.765 , so $\epsilon=1-0.765=0.235$.

15 It approaches zero as $\theta$ approaches zero, it is increasing in $\theta$, and it approaches $\infty$ as $\theta$ approaches $\infty$. Thus, it is positive for all $\theta \geq 0$.
} 
The intuition of Proposition 1 is simple. An increase in the capital tax of jurisdiction $i$ lowers the net return to capital in jurisdiction $i$, inducing capital to move out of jurisdiction $i$ and decreasing $k_{i}$. To restore labor market equilibrium condition (9), $\theta_{i}$ decreases to maximize the workers' utility and the firms' profits in a new labor market equilibrium, given that $A_{i k}>0$ and $A_{i \theta}<0$. The comparative statics result is thus an outcome of the interaction between the labor market and the capital market in response to an increase in the capital tax. Other comparative statics results in (12) can be understood in an analogous manner.

The proposition shows that the capital tax affects employment. In particular, an increase in the capital tax is detrimental to employment, a result consistent with an observation that policymakers of a jurisdiction provide tax incentives to bring jobs to the jurisdiction, as noted in the Introduction. By contrast, in earlier standard models of tax competition (Wilson 1986; Zodrow and Mieszkowski 1986; Wildasin 1989), full employment is assumed, as the models focus on the role of the mobility of capital in determining the efficiency of the capital tax. As a result, the capital tax has no effect on employment in such models. More recently, a literature has considered imperfect labor markets in tax competition models, as noted above, but the literature has mainly studied the effects of imperfect labor markets on inefficiency of capital taxation, rather than the effects of capital taxes on employment.

The proposition discussed the role of the capital tax in capital employment and vacancies, but it is also meaningful to consider the role of capital in the creation of vacancies or jobs. Since capital investment by a firm of jurisdiction $i, k_{i}$, is endogenous, the role of capital cannot be directly examined. However, the role of capital supply $\bar{K}$ can be discussed. Suppose first that the economy is closed and capital is not mobile. Then, only two conditions are relevant: labor market equilibrium condition (9) and a local capital market equilibrium condition, $k_{i} \theta_{i}=\bar{K}_{i}$. Solving two equations for $k_{i}$ and $\theta_{i}$, it can be easily shown that $\partial k_{i} / \partial \bar{K}_{i}>0$ and $\partial \theta_{i} / \partial \bar{K}_{i}>0$. Thus, an increase in the supply of capital to a jurisdiction increases capital investment by a firm and the number of vacancies or jobs in the jurisdiction. To the extent that jurisdictions differ in the supply of capital, this result means that a jurisdiction with a higher level of capital creates more vacancies. If the economy is open and capital is mobile, in a manner analogous to (12), it is again straightforward to show that $\partial \theta_{i} / \partial \bar{K}_{s}>0$ and $\partial \theta_{i} / \partial \bar{K}_{s} \geq 0, s=i, j$, so the same result can be obtained if the international supply of capital, $\bar{K}_{1}+\bar{K}_{2}$, increases.

Since the wages and employment are jointly determined in the labor market equilibrium and the capital market equilibrium, the effects of the capital taxes on the wages also can be considered. In particular, using (6),

$$
\begin{aligned}
& \frac{\partial w_{i}}{\partial t_{i}}=\frac{\partial}{\partial t_{i}}\left[f_{i}-k_{i} f_{i}^{\prime}\right]=\left[-k_{i} f_{i}^{\prime \prime}\right] \frac{\partial k_{i}}{\partial t_{i}}<0, \\
& \frac{d\left(\mu_{i} w_{i}\right)}{d t_{i}}=\mu_{i}^{\prime} \frac{\partial \theta_{i}}{\partial t_{i}} w_{i}+\mu_{i} \frac{\partial w_{i}}{\partial t_{i}}<0,
\end{aligned}
$$

where the first inequality follows from $\partial k_{i} / \partial t_{i}<0$ in (12), and the second one comes from $\mu_{i}^{\prime}>0$ and $\partial \theta_{i} / \partial t_{i}<0$ in (12). These results can be stated as follows: 
Proposition 2 Assume (16). $\partial w_{i} / \partial t_{i}<0, d\left(\mu_{i} w_{i}\right) / d t_{i}<0, \partial w_{j} / \partial t_{i}>0$, and $d\left(\mu_{j} w_{j}\right) / d t_{i}>0$ (an increase in the capital tax of a jurisdiction decreases the wage and the expected wage of the jurisdiction but increases the wage and the expected wage of the other jurisdiction).

The result has a simple intuition. An increase in the capital tax of a jurisdiction discourages firms from investing in capital $\left(\partial k_{i} / \partial t_{i}<0\right)$, as in (12). A lower investment in capital in turn decreases output $f_{i}\left(k_{i}\right)$ of a firm and hence the wage it pays. Since an increase in $t_{i}$ also lowers $\theta_{i}$ from (12), it also decreases the expected wage, $\mu_{i} w_{i}$. The proposition may explain why policymakers provide tax incentives to attract capital.

While the proposition is simple, it illustrates a difference from the standard tax competition models (Wilson 1986; Zodrow and Mieszkowski 1986; Wildasin 1989). In the standard models, the production function $f(k, \ell)$ exhibits constant returns to scale with $\ell$ denoting labor. Factor markets are competitive, and each factor is paid its marginal product and the wage equals $\partial f / \partial \ell=[f-k(\partial f / \partial k)] / \ell$ due to the constant-returns-to-scale assumption. Thus, attraction of capital increases the wage, as $d[(f-k(\partial f / \partial k)) / \ell)] / d k=-k\left(\partial^{2} f / \partial k^{2}\right) / \ell>0$. The wage increases in the standard models due to the complementarity between labor and capital. That is, more capital increases the marginal product of labor due to the complementarity. By contrast, in the present model, a decrease in the capital tax encourages firms to invest in capital in the labor market equilibrium, increasing output and hence the wages. A more recent literature on tax competition with imperfect labor markets again has mainly concerned inefficiency of capital taxation rather than the effects of capital taxes on wages.

\section{Inefficiency of capital taxes}

The utility of the resident of jurisdiction $i$ is

$$
U_{i}=\mu_{i}\left(\theta_{i}\right) u_{i}\left(f_{i}\left(k_{i}\right)-k_{i} f_{i}^{\prime}\left(k_{i}\right)+\rho \bar{K}_{i}\right)+\left(1-\mu_{i}\left(\theta_{i}\right)\right) u_{i}\left(\rho \bar{K}_{i}\right)+v_{i}\left(z_{i}\right) .
$$

Assuming that one unit of the private good can be transformed into one unit of the public good,

$$
z_{i}=t_{i} \theta_{i} k_{i} .
$$

From Proposition $1, k_{i}$ and $\theta_{i}$ depend on $t_{i}$ and $t_{j}$, and so does $U_{i}$. The government of jurisdiction $i$ then chooses $t_{i}$ to maximize $U_{i}$, taking $t_{j}$ as given. The FOC for an interior maximum of $U_{i}$ with respect to $t_{i}$ reads 


$$
\begin{aligned}
& \frac{\partial U_{i}}{\partial t_{i}}=v_{i}^{\prime}\left[\theta_{i} k_{i}+t_{i}\left(k_{i} \frac{\partial \theta_{i}}{\partial t_{i}}+\theta_{i} \frac{\partial k_{i}}{\partial t_{i}}\right)\right] \\
& \quad+\mu_{i} u_{i e}^{\prime}\left(-k_{i} f_{i}^{\prime \prime}\right) \frac{\partial k_{i}}{\partial t_{i}} \\
& \quad+\mu_{i}^{\prime}\left(u_{i e}-u_{i u}\right) \frac{\partial \theta_{i}}{\partial t_{i}} \\
& +\left[\mu_{i} u_{i e}^{\prime}+\left(1-\mu_{i}\right) u_{i u}^{\prime}\right] \frac{\partial \rho}{\partial t_{i}} \bar{K}_{i}=0, i=1,2,
\end{aligned}
$$

and let $t_{i}^{*}$ denote the equilibrium tax that satisfies FOC (20). As the public good is financed by the capital tax, it is assumed that $t_{i}^{*}>0$ and the public good is provided. Throughout the analysis, the second-order condition is assumed to be satisfied. The first line is the effect of an increase in the capital tax on the public good. An increase in the capital tax increases the public good at a given level of capital $\theta_{i} k_{i}$, but it also drives capital out and decreases the public good. The second line represents the effect on the wage arising from a reduction in firms' investment in capital $k_{i}$. The third line shows the effect on the employment rate arising from a decrease in the number of vacancies or market tightness $\theta_{i}$. The last one is the effect on the net return to capital owned (the capital income earned) by the resident of the jurisdiction.

To see inefficiency of the capital tax, consider the efficient $t_{i}$ that maximizes the social welfare $W=U_{1}+U_{2}$ and satisfies the FOC

$$
\frac{d W}{d t_{i}}=\frac{\partial U_{i}}{\partial t_{i}}+\frac{\partial U_{j}}{\partial t_{i}}=0,
$$

where

$$
\begin{aligned}
& \frac{\partial U_{j}}{\partial t_{i}}=v_{j}^{\prime} t_{j}\left(k_{j} \frac{\partial \theta_{j}}{\partial t_{i}}+\theta_{j} \frac{\partial k_{j}}{\partial t_{i}}\right) \\
& \quad+\mu_{j} u_{j e}^{\prime}\left(-k_{j} f_{j}^{\prime \prime}\right) \frac{\partial k_{j}}{\partial t_{i}} \\
& \quad+\mu_{j}^{\prime}\left(u_{j e}-u_{j u}\right) \frac{\partial \theta_{j}}{\partial t_{i}} \\
& \quad+\left[\mu_{j} u_{j e}^{\prime}+\left(1-\mu_{j}\right) u_{j u}^{\prime}\right] \frac{\partial \rho}{\partial t_{i}} \bar{K}_{j}, i \neq j, i, j=1,2 .
\end{aligned}
$$

It is in general not possible to compare the equilibrium tax and the efficient tax, and the comparison is usually made based on symmetric jurisdictions with $u_{1}=u_{2}=u, v_{1}=v_{2}=v, f_{1}=f_{2}=f, k_{1}=k_{2}=k, \theta_{1}=\theta_{2}=\theta, \bar{K}_{1}=\bar{K}_{2}=\bar{K}=\theta k, \mu_{1}=\mu_{2}=\mu \quad$ and $\eta_{1}=\eta_{2}=\eta$. With symmetric jurisdictions,

$$
\frac{\partial \theta_{j}}{\partial t_{i}}=-\frac{\partial \theta_{i}}{\partial t_{i}}, \text { and } \frac{\partial k_{j}}{\partial t_{i}}=-\frac{\partial k_{i}}{\partial t_{i}}
$$


from (12). In addition, with symmetric jurisdictions,

$$
\frac{\partial \rho}{\partial t_{i}}=\frac{\partial\left(\eta_{i} f_{i}^{\prime}-t_{i}\right)}{\partial t_{i}}=\eta_{i} f_{i}^{\prime \prime} \frac{\partial k_{i}}{\partial t_{i}}+\eta_{i}^{\prime} f_{i}^{\prime} \frac{\partial \theta_{i}}{\partial t_{i}}-1=-\frac{1}{2}
$$

in (12) by using the definition of $D$ in (13). (24) implies

$$
\eta_{i} f_{i}^{\prime \prime} \frac{\partial k_{i}}{\partial t_{i}}+\eta_{i}^{\prime} f_{i}^{\prime} \frac{\partial \theta_{i}}{\partial t_{i}}=\frac{1}{2}
$$

Adding (20) and (22), (21) reduces to

$$
\frac{d W}{d t_{i}}=\left[v^{\prime}-\mu u_{e}^{\prime}-(1-\mu) u_{u}^{\prime}\right] \theta k=0 \Longrightarrow \mu u_{e}^{\prime}+(1-\mu) u_{u}^{\prime}=v^{\prime} .
$$

The efficient capital tax, denoted $\hat{t}_{i}$, thus equates the marginal utility of the public good, $v^{\prime}$, with the marginal cost of the capital tax, $\mu u_{e}^{\prime}+(1-\mu) u_{u}^{\prime}$. Intuitively, the mobility of capital does not matter to the social planner that cares about the welfare of both jurisdictions, as the supply of capital to the economy is fixed.

Using (26), evaluation of (20) at $\hat{t}_{i}$ gives, with symmetric jurisdictions (although jurisdictional subscripts $i$ are kept to keep track of derivatives such as $\left.\partial k_{i} / \partial t_{i}\right)$,

$$
\begin{aligned}
& \left.\frac{\partial U_{i}}{\partial t_{i}}\right|_{t_{i}=\hat{t}_{i}}=v_{i}^{\prime}\left[\theta_{i} k_{i}+\hat{t}_{i}\left(k_{i} \frac{\partial \theta_{i}}{\partial t_{i}}+\theta_{i} \frac{\partial k_{i}}{\partial t_{i}}\right)\right] \\
& +\mu_{i} u_{i e}^{\prime}\left(-k_{i} f_{i}^{\prime \prime}\right) \frac{\partial k_{i}}{\partial t_{i}} \\
& +\mu_{i}^{\prime}\left(u_{i e}-u_{i u}\right) \frac{\partial \theta_{i}}{\partial t_{i}} \\
& +v_{i}^{\prime} \frac{\partial \rho}{\partial t_{i}} \theta_{i} k_{i} .
\end{aligned}
$$

To see (27), it proves useful to first consider the standard result without unemployment or matching frictions in the present framework. Without labor market frictions, $u_{e}=u_{u}=u, \mu=\eta=1, \mu^{\prime}=\eta^{\prime}=0$, and $\partial \theta_{i} / \partial t_{i}=0$. The third line of (27) then vanishes, and the second line becomes

$$
u_{i e}^{\prime}\left(-k_{i} f_{i}^{\prime \prime}\right) \frac{\partial k_{i}}{\partial t_{i}}=-\frac{1}{2} u_{i e}^{\prime} k_{i}=-\frac{1}{2} v_{i}^{\prime} k_{i}
$$

where the first equality comes from $\partial k_{i} / \partial t_{i}=1 / 2 f_{i}^{\prime \prime}$ with $\eta=1, \eta^{\prime}=0$ and symmetric jurisdictions in (12), and the second one uses $u_{i e}^{\prime}=v_{i}^{\prime}$ with $\mu=1$ in (26). (27) then reduces to

$$
\left.\frac{\partial U_{i}}{\partial t_{i}}\right|_{t_{i}=\hat{t}_{i}}=v_{i}^{\prime}\left[k_{i}+\hat{t}_{i} \frac{\partial k_{i}}{\partial t_{i}}-\frac{1}{2} k_{i}-\frac{1}{2} k_{i}\right]=v_{i}^{\prime} \hat{t}_{i} \frac{\partial k_{i}}{\partial t_{i}}<0,
$$

where the equality comes from (24), (28) and $\theta=1$. Thus, $t_{i}^{*}<\hat{t}_{i}$ and the equilibrium capital tax is lower than the efficient tax, because an increase in $t_{i}$ drives out 
capital to jurisdiction $j$ and increases the tax revenue and hence the public good of jurisdiction $j$ but jurisdiction $i$ does not consider this external benefit (positive externality) it confers on jurisdiction $j$.

With matching frictions, two additional factors have to be considered when comparing the equilibrium tax and the efficient tax. First, since $\mu^{\prime}>0$ and $\partial \theta_{i} / \partial t_{i}<0$, the third line of (27) does not vanish but is negative. Second, $\partial k_{i} / \partial t_{i}$ does not reduce to $1 / 2 f_{i}^{\prime \prime}$ unlike in (28), and the second line of (27) becomes more complicated. The second line and the third line become

$$
\begin{aligned}
& \mu_{i} u_{i e}^{\prime}\left(-k_{i} f_{i}^{\prime \prime}\right) \frac{\partial k_{i}}{\partial t_{i}}+\mu_{i}^{\prime}\left(u_{i e}-u_{i u}\right) \frac{\partial \theta_{i}}{\partial t_{i}} \\
& =\mu_{i} u_{i e}^{\prime}\left(-k_{i} f_{i}^{\prime \prime}\right) \frac{\partial k_{i}}{\partial t_{i}}+\eta \epsilon u_{i e}^{\prime} k_{i} f_{i}^{\prime} \frac{\partial \theta_{i}}{\partial t_{i}} \\
& =-u_{i e}^{\prime} \theta_{i} k_{i}\left[\eta_{i} f_{i}^{\prime \prime} \frac{\partial k_{i}}{\partial t_{i}}+\eta_{i}^{\prime} f_{i}^{\prime} \frac{\partial \theta_{i}}{\partial t_{i}}\right]=-\frac{1}{2} u_{i e}^{\prime} \theta_{i} k_{i},
\end{aligned}
$$

where the first equality uses (9), the second one comes from rearrangement of terms, and the last one comes from (25). (27) becomes then

$$
\begin{gathered}
\left.\frac{\partial U_{i}}{\partial t_{i}}\right|_{t_{i}=\hat{t}_{i}}=v_{i}^{\prime} \hat{t}_{i}\left(k_{i} \frac{\partial \theta_{i}}{\partial t_{i}}+\theta_{i} \frac{\partial k_{i}}{\partial t_{i}}\right)+v_{i}^{\prime} \theta_{i} k_{i}-\frac{1}{2} u_{i e}^{\prime} \theta_{i} k_{i}-\frac{1}{2} v_{i}^{\prime} \theta_{i} k_{i} \\
=v_{i}^{\prime} \hat{t}_{i}\left(k_{i} \frac{\partial \theta_{i}}{\partial t_{i}}+\theta_{i} \frac{\partial k_{i}}{\partial t_{i}}\right)+\frac{1}{2} \theta_{i} k_{i}\left(1-\mu_{i}\right)\left(u_{i u}^{\prime}-u_{i e}^{\prime}\right),
\end{gathered}
$$

where the equality uses (26).

The first term of (31) is negative and represents the standard positive externality in the literature, associated with an increase in the tax revenues of jurisdiction $j$ caused by an increase in $t_{i}$ and the exodus of capital to jurisdiction $j$. This positive externality is written as $\hat{t}_{j}\left(k_{j} \frac{\partial \theta_{j}}{\partial t_{i}}+\theta_{j} \frac{\partial k_{j}}{\partial t_{i}}\right)>0$. The only difference from the standard positive externality is that the tax revenues are $t_{j} \theta_{j} k_{j}$ rather than $t_{j} k_{j}$ due to frictions. The second term is positive and shows the new negative externality jurisdiction $i$ imposes on jurisdiction $j$ due to matching frictions. As in the standard model, an increase in $t_{i}$ and the exodus of capital to jurisdiction $j$ increases the (expected) wage of the resident of jurisdiction $j$ by $d\left[\mu_{j}\left(f_{j}-k_{j} f_{j}^{\prime}\right)\right] / d t_{i}=\mu_{j}^{\prime}\left(f_{j}-k_{j} f_{j}^{\prime}\right) \frac{\partial \theta_{j}}{\partial t_{i}}-\mu_{j} k_{j} f_{j}^{\prime \prime} \frac{\partial k_{j}}{\partial t_{i}}$ and decreases the (expected) gross return to capital of the resident of jurisdiction $j$ by $d\left(\eta_{j} f_{j}^{\prime} \bar{K}_{j}\right) / d t_{i}=\left(\eta_{j} f_{j}^{\prime \prime} \frac{\partial k_{j}}{\partial t_{i}}+\eta_{j}^{\prime} f_{j}^{\prime} \frac{\partial \theta_{j}}{\partial t_{i}}\right) k_{j} \theta_{j}$. These two quantities are the same in absolute value and cancel out, as $\mu^{\prime}=\eta(1-\epsilon)$ in $(8)$ and $(1-\epsilon)\left(f-k f^{\prime}\right)-\epsilon k f^{\prime}=0$ in (9) with risk neutrality or $u^{\prime}=1$. In fact, the second term of (31) vanishes when $u_{i u}^{\prime}=u_{i e}^{\prime}=$ constant . However, the residents of jurisdiction $j$ enjoy the wages only when they are employed, but enjoy the return to capital regardless of whether they are employed or not. Since they have a higher income when employed than when unemployed, risk aversion implies that the utility gain of the increase in the wage is less than the utility loss of the decrease in the return to capital. Thus, an increase in $t_{i}$ decreases the utility of the residents of jurisdiction $j$, imposing a negative 
externality. Due to the traditional positive externality in the first term of (31) and the new negative one in the second term, the sign of (31) cannot be determined. This discussion underscores the importance of risk aversion in the presence of matching frictions and possible unemployment, but to the best of my knowledge, risk aversion has not been considered in tax competition models. The ambiguous sign of (31) leads to the following result:

Proposition 3 With symmetric jurisdictions, $t^{*} \leq \hat{t}$ or $\geq \hat{t}$ (the equilibrium capital tax may be too low or too high relative to the efficient tax).

The proposition stands in contrast with the standard result that the equilibrium capital tax is lower than the efficient one (Wilson 1986; Zodrow and Mieszkowski 1986). The proposition is not the only exception to the standard result, and other papers also demonstrate that the equilibrium capital tax may be higher than the efficient one for other reasons. For example, Wildasin and Wilson (1998) and Lee (2003) show that the equilibrium capital tax can be higher than the efficient tax when absentee owners own immobile factors such as land. Lee (1997) and Wildasin (2003) show that when capital is imperfectly mobile, jurisdictions may overtax capital in an attempt to exploit imperfect mobility. In Ogawa et al. (2006) and Eichner and Upmann $(2012,2014)$, the possibility of too high or too low a capital tax occurs due to the distortions created by a fixed wage or bargains between a labor union and an employers' association, and depends on whether labor and capital are substitutes or complements, as noted earlier. In this paper, the partial benefits of capital on the wages due to possible unemployment, combined with risk aversion, play an important role in determining the relationship between the equilibrium capital tax and the efficient tax.

The analysis has assumed that the efficient tax $\hat{t}$ maximizes social welfare $W=U_{1}+U_{2}$. If a Pareto-efficient tax is considered, it maximizes $U_{i}+\delta\left[U_{j}-\underline{u}_{j}\right]$ with $\delta$ and $\underline{u}_{j}$ denoting a positive multiplier and a fixed utility. It can be shown in Appendix that $\left.\frac{\partial U_{i}}{\partial t_{i}}\right|_{t_{i}=\hat{t}_{i}}$ becomes (31) times $\delta$, which has no effect on the sign (31). Thus, the same result holds.

To have a sense of the relationship between $t^{*}$ and $\hat{t}$ in Proposition 3 , the sign of (31) has to be determined. Given the complexity of (31), a very simple example is considered,

$$
f(k)=\alpha k-k^{2}, u(y)=\beta y-y^{2}, v(z)=z, \mu(\theta)=\frac{\theta}{1+\theta} .
$$

Appendix shows that the relationship depends in part on the magnitude of $\beta$. In particular, the larger $\beta$, the more likely $t^{*}>\hat{t}$. Intuitively, $\beta$, as the preference parameter, plays two roles in the relationship between $t^{*}$ and $\hat{t}$. First, the efficient $\operatorname{tax} \hat{t}$ in (26) depends on the shape of the utility function and hence $\beta$. Second, the externality in (31) depends on $u_{e}^{\prime}$ and $u_{u}^{\prime}$ and hence on $\beta$. However, if evaluated at the efficient tax rate $\hat{t}, u_{e}^{\prime}$ and $u_{u}^{\prime}$ do not depend on $\beta$ any longer. The reason is that $u_{e}^{\prime}$ and $u_{u}^{\prime}$ are related to $v^{\prime}(z)$ in (26), but not to $\beta$. Thus, only the first effect of $\beta$ on the efficient tax rate $\hat{t}$ matters. Since $u^{\prime}(y)=\beta-2 y$ and a larger $\beta$ means a higher marginal 
utility, the larger $\beta$, the higher the utility cost of raising the tax to provide the public good. The planner thus decreases $\hat{t}$ as $\beta$ increases, which makes it more likely that the equilibrium $\operatorname{tax} t^{*}$ is higher than the efficient tax $\hat{t}$. This result can be related to risk aversion. Absolute risk aversion is $-u^{\prime \prime} / u^{\prime}=2 /(\beta-2 y)$, which decreases in $\beta$ and increases in income $y$. An individual with a higher $\beta$ thus behaves like a lower income individual in terms of risk preferences. Due to the diminishing marginal utility of income, a lower income increases the marginal utility and hence increases the utility cost of raising the tax, and the planner chooses a lower tax $\hat{t}$ for less riskaverse individuals with larger $\beta$. The production-function parameter $\alpha$ also matters, but its effect on the relationship between $t^{*}$ and $\hat{t}$ is too complicated to be determined even with the simple example, as it affects the efficient tax and the terms involving $\partial k_{i} / \partial t_{i}$ and $\partial \theta_{i} / \partial t_{i}$

The analysis has shown that risk aversion plays an important role in tax competition with labor market frictions. The role of risk aversion appears to be more general than the analysis suggests and is extended to other settings. First, in the literature on asymmetric tax competition, a small country tends to benefit from tax coordination that increases the capital taxes, as it imports capital from a large country and wants to decrease the price of capital by raising the tax (Peralta and Van Ypersele 2006; Keen and Konrad 2013). However, the utility gain from more capital and higher wages for the small country would be smaller, and the result may have to be modified to the extent that workers are risk averse and labor markets are imperfect. That is, the wage gain is realized only when a worker is employed and has a higher income, so risk aversion implies that the utility benefit from the wage gain is smaller than the utility loss from the decrease in the capital income from higher taxes.

Second, job training for low-skilled workers has been an important labor market policy. Training increases the productivity/wage and the likelihood of employment by increasing basic skills, but tends to increase the wage more than the employability (McKenzie 2017; Attanasio et al. 2011). This finding is consistent with an observation that labor market frictions affect labor market outcomes, and employment and unemployment are subject to random factors. The utility benefit of job training for risk-averse workers thus may be limited to the extent that training mainly increases the wages, because the wage gain from training is realized only when workers are employed and hence have a higher income. By contrast, job search assistance programs reduce frictions and increase employment (Graversen and Van Ours 2008; Gautier et al. 2018), providing a more direct utility benefit than training. This difference between job training and search assistance is particularly important for low-skilled workers, as they are known to be more risk averse (Swanson 2020) and the utility benefit of training for them is smaller.

Among policies for low-income individuals, the Earned Income Tax Credit (EITC) is considered an effective welfare policy in the sense that it encourages the recipients to work, unlike cash transfers such as the Temporary Assistance for Needy Families program (Meyer and Rosenbaum 2001; Bastian 2020). However, the utility benefit of the EITC would be lower for risk-averse workers, as they enjoy the benefit of the EITC only when they are employed and hence have higher incomes. By contrast, a universal basic income is provided regardless of whether one is employed or not, so it suffers less from the utility effect associated with risk aversion. This discussion is not intended 
to compare or analyze welfare policies but simply to relate the role of risk aversion to such policies. Incidentally, universal basic incomes have recently gained traction both in academia (Daruich and Fernández 2020) and in policy circles (Stevens and Grullón Paz 2020) although the reasons for universal basic incomes differ and risk aversion has not been a factor in the literature or policy debates. In a similar vein, during the recent Covid-19 pandemic, the USA has implemented a type of a universal basic income, namely stimulus checks distributed to almost all Americans, over payroll tax cuts as a way of helping the unemployed and stimulating the economy.

\section{Head tax and capital tax}

This section considers capital tax competition with a head tax, $H_{i}$. The head tax is not meant to be realistic but helps in understanding the role of the capital tax in the presence of a non-distortionary tax. In a manner analogous to (12) and (13), total differentiation of (9) through (11) can show that ${ }^{16}$

$$
\begin{aligned}
\frac{\partial \theta_{i}}{\partial H_{i}} & =\frac{1}{D} A_{i H}\left[A_{j \theta}\left(\eta_{i} f_{i}^{\prime \prime} \theta_{j}+\eta_{j} f_{j}^{\prime \prime} \theta_{i}\right)-A_{j k}\left(\eta_{i} f_{i}^{\prime \prime} k_{j}+\eta_{j}^{\prime} f_{j}^{\prime} \theta_{i}\right)\right], \\
\frac{\partial \theta_{j}}{\partial H_{i}} & =\frac{1}{D} A_{i H} A_{j k}\left(\eta_{i} f_{i}^{\prime \prime} k_{i}-\eta_{i}^{\prime} f_{i}^{\prime} \theta_{i}\right), \\
\frac{\partial k_{i}}{\partial H_{i}} & =\frac{1}{D} A_{i H}\left[A_{j k}\left(\eta_{i}^{\prime} f_{i}^{\prime} k_{j}+\eta_{j}^{\prime} f_{j}^{\prime} k_{i}\right)-A_{j \theta}\left(\eta_{i}^{\prime} f_{i}^{\prime} \theta_{j}+\eta_{j} f_{j}^{\prime \prime} k_{i}\right)\right], \\
\frac{\partial k_{j}}{\partial H_{i}} & =\frac{1}{D} A_{i H} A_{j \theta}\left(\eta_{i}^{\prime} f_{i}^{\prime} \theta_{i}-\eta_{i} f_{i}^{\prime \prime} k_{i}\right), \\
\frac{\partial \rho}{\partial H_{i}} & =\frac{1}{D} A_{i H}\left[\left(A_{j k} \eta_{j}^{\prime} f_{j}^{\prime}-A_{j \theta} \eta_{j} f_{j}^{\prime \prime}\right)\left(\eta_{i} f_{i}^{\prime \prime} k_{i}-\eta_{i}^{\prime} f_{i}^{\prime} \theta_{i}\right)\right], i \neq j, i, j=1,2,
\end{aligned}
$$

where

$$
A_{i H} \equiv \frac{\partial A_{i}}{\partial H_{i}}=\left(1-\epsilon_{i}\right)\left[u_{i u}^{\prime}-u_{i e}^{\prime}\right]+\epsilon_{i} u_{i e}^{\prime \prime} k_{i} f_{i}^{\prime}, i=1,2 .
$$

The sign of $A_{i H}$, and hence the signs of comparative statics results in (32), cannot be determined in general. As in Appendix,

$$
A_{i H}>(=,<) 0 \text { if } D A R A(C A R A, I A R A),
$$

where DARA (CARA, IARA) means decreasing (constant, increasing) absolute risk aversion.

The government of jurisdiction $i$ chooses $\left(t_{i}, H_{i}\right)$, taking $\left(t_{j}, H_{i}\right)$ as given, to maximize $U_{i}$. The FOC with respect to $H_{i}$ reads

\footnotetext{
16 A non-wage income $w_{o}$ can be added, so that a worker can pay the head tax even if the worker is unemployed. However, it has no effect on the analysis or result, so it is suppressed.
} 


$$
\begin{aligned}
& \frac{\partial U_{i}}{\partial H_{i}}=v_{i}^{\prime}\left[1+t_{i}\left(k_{i} \frac{\partial \theta_{i}}{\partial H_{i}}+\theta_{i} \frac{\partial k_{i}}{\partial H_{i}}\right)\right] \\
& -\left[\mu_{i} u_{i e}^{\prime}+\left(1-\mu_{i}\right) u_{i u}^{\prime}\right] \\
& +\mu_{i} u_{i e}^{\prime}\left(-k_{i} f_{i}^{\prime \prime}\right) \frac{\partial k_{i}}{\partial H_{i}} \\
& +\mu_{i}^{\prime}\left(u_{i e}-u_{i u}\right) \frac{\partial \theta_{i}}{\partial H_{i}} \\
& +\left[\mu_{i} u_{i e}^{\prime}+\left(1-\mu_{i}\right) u_{i u}^{\prime}\right] \frac{\partial \rho}{\partial H_{i}} \bar{K}_{i}=0, i=1,2,
\end{aligned}
$$

and let $H_{i}^{*}$ satisfy FOC (35). FOC (35) differs from (20), the FOC with respect to the capital tax $t_{i}$, in three respects. First, as in the first line, an increase in $H_{i}$ by one unit increases the public good by one unit rather than by $\theta_{i} k_{i}$. Second, as in the second line, the head tax directly reduces the disposable incomes and hence the utility by $\left[\mu_{i} u_{i e}^{\prime}+\left(1-\mu_{i}\right) u_{i u}^{\prime}\right]$. Third, $\partial \theta_{i} / \partial H_{i}, \partial k_{i} / \partial H_{i}$ and $\partial \rho / \partial H_{i}$ replace $\partial \theta_{i} / \partial t_{i}, \partial k_{i} / \partial t_{i}$ and $\partial \rho / \partial t_{i}$, respectively.

To see the role of the capital tax in the presence of the head tax in the simplest manner, assume first CARA. CARA not only simplifies the analysis, but also makes clearer the comparison between the standard model and the model here with labor market frictions. With CARA, $A_{i H}=0$ in (34) and hence $\partial \theta_{i} / \partial H_{i}=\partial k_{i} / \partial H_{i}=\partial \rho / \partial H_{i}=0$. FOC (35) then reduces to $v_{i}^{\prime}-\left[\mu_{i} u_{i e}^{\prime}+\left(1-\mu_{i}\right) u_{i u}^{\prime}\right]=0$. Since the efficient capital tax satisfies the same condition, as in (26), the head tax serves as the efficient capital tax with CARA. This interpretation of the head tax is consistent with the standard model of tax competition. Evaluating FOC (20) at $t=0$ and $H_{i}=H_{i}^{*},{ }^{17}$

$$
\left.\frac{\partial U_{i}}{\partial t_{i}}\right|_{\left(t_{i}=0, H_{i}=H_{i}^{*}\right)}=\frac{1}{2} \theta_{i} k_{i}\left(1-\mu_{i}\right)\left(u_{i u}^{\prime}-u_{i e}^{\prime}\right)>0 .
$$

The inequality in (36) implies the following ${ }^{18}$ :

Proposition 4 Assume CARA. With symmetric jurisdictions, $t_{i}^{*}>0$ with $H_{i}=H_{i}^{*}$ (capital is taxed even if the head tax is available).

To see the intuition of the proposition, observe that an increase in the capital tax by one unit decreases the expected utility from a lower expected wage by $\mu^{\prime}\left(u_{e}-u_{u}\right) \frac{\partial \theta_{i}}{\partial t_{i}}+\mu u_{e}^{\prime}\left(-k f^{\prime \prime}\right) \frac{\partial k_{i}}{\partial t_{i}}$ and decreases the expected utility from a lower expected net capital income by $\left[\mu u_{e}^{\prime}+(1-\mu) u_{u}^{\prime}\right] \bar{K} \frac{\partial \rho}{\partial t_{i}}=v^{\prime}\left(-\frac{1}{2}\right) \theta k$ due to (24) and $v^{\prime}=\left[\mu u_{e}^{\prime}+(1-\mu) u_{u}^{\prime}\right]$ with the head tax chosen. The sum of these two quantities equals (30) minus $\frac{1}{2} v^{\prime} \theta k$. The increase in the capital tax by one unit also increases the utility from a higher level of public good consumption by $v^{\prime}\left[\theta k+t\left(\theta \frac{\partial k_{i}}{\partial t_{i}}+k \frac{\partial \theta_{i}}{\partial t_{i}}\right)\right]$,

17 Since (26) holds with the head tax chosen, (31) continues to hold. With $t_{i}=0,(31)$ reduces to (36).

18 As noted earlier, the second-order condition is assumed satisfied. 
which reduces to $v^{\prime} \theta k$ at $t=0$. Thus, the total effect of the increase in the capital tax by one unit on the utility of the resident of jurisdiction $i$ amounts to (31) minus $v_{i}^{\prime} \hat{t}_{i}\left(k_{i} \frac{\partial \theta_{i}}{\partial t_{i}}+\theta_{i} \frac{\partial k_{i}}{\partial t_{i}}\right)$, which is (36) and positive, so it pays to tax capital.

The proposition stands in contrast with the standard result that the head tax obviates the need for the capital tax, because the capital tax is distortionary, while the head tax is not (Wilson 1986; Zodrow and Mieszkowski 1986). Other papers also show that capital may be taxed or subsidized even with the head tax. For instance, capital is still taxed when profits cannot be taxed in a monopsony model (Richter and Schneider 2001), or when firms are owned by foreigners (Sørensen 2004), or when residents of a jurisdiction differ in their endowments of mobile capital and an immobile factor (Braulke and Corneo 2004; Lee 2012), or when labor and capital are substitutes in a model with a fixed wage (Ogawa et al. 2006). However, the sign of (34), and hence whether capital is taxed or subsidized, does not depend on monopsony or foreign ownership of firms or factor endowments of the residents or the relationship between capital and labor. Rather, it hinges on risk aversion and labor market frictions with which more capital increases the wages only when workers are employed. Alternatively speaking, matching frictions and possible unemployment lower the cost of taxing capital stemming from capital flight and lower wages, encouraging a jurisdiction to tax capital more than in perfect labor markets. The analysis here does not argue that capital is necessarily taxed even with a nondistortionary tax, because there may be other reasons why capital may be subsidized. Rather, the proposition shows that labor market frictions are a factor that encourages taxation of capital even if the head tax is available.

In general without CARA, using (32), (33) and (35), it is straightforward to verify that

$$
v^{\prime}<(=,>) \mu u_{e}^{\prime}+(1-\mu) u_{u}^{\prime} \text { if } \operatorname{DARA}(C A R A, I A R A)
$$

when the head tax is chosen and FOC (35) is satisfied. As a result, (36) does not hold. With IARA, (36) become

$$
\frac{1}{2} \theta_{i} k_{i}\left(v_{i}^{\prime}-u_{i e}^{\prime}\right)>\frac{1}{2} \theta_{i} k_{i}\left[\mu_{i} u_{i e}^{\prime}+\left(1-\mu_{i}\right) u_{i u}^{\prime}-u_{i e}^{\prime}\right]=\frac{1}{2} \theta_{i} k_{i}\left(1-\mu_{i}\right)\left(u_{i u}^{\prime}-u_{i e}^{\prime}\right)>0,
$$

reinforcing the inequality in (36) and extending Proposition 4 to IARA. With DARA, the first inequality is reversed, making ambiguous the direction of inequality in (36). Thus, capital may be still taxed or subsidized with the head tax.

\section{Conclusion}

The tax competition literature has focused on the incentives of jurisdictions to attract mobile capital by undertaxing capital. The labor-market matching literature has mainly studied the effects of matching frictions on labor market outcomes. This paper combines the two strands of literature by including mobile capital in a model with labor market frictions, thereby enabling the analysis of the role of capital in 
labor market outcomes and the effects of matching frictions on inefficiency of capital taxes.

As discussed in Introduction, policymakers, both at a national level and at a local level, appear to care about jobs, and accordingly make policies to bring jobs to their countries or localities. In fact, according to the most recent Gallup poll in October 2019, "unemployment/jobs" is the most important economic problem right after "economy in general" facing Americans even with the unemployment rate below $4 \% .{ }^{19}$ In terms of the utility in the analysis, an increase in employment of a jurisdiction increases the well-being of the residents of the jurisdiction, as $u_{i e}>u_{i u}$. This discussion illustrates the potential value of studying unemployment and jobs in tax competition models, especially because jobs have been mentioned as a reason for attracting capital.

The analysis here provides an insight for policies in relation to unemployment and labor market frictions. In particular, capital is beneficial, as it increases the wages, but the benefit occurs only when workers are employed. The presence of unemployment thus dilutes the value of capital relative to the perfect-labor-market case, which in turn reduces the desire to attract capital by cutting capital taxes excessively. As a result, tax competition may not be as inefficient as thought in the perfect-labormarket case, and a higher-level government may not have to aggressively regulate or co-ordinate capital tax policies made by self-interested jurisdictions.

Matching frictions seem to influence labor markets significantly, and it appears to be fruitful to study the role of capital in labor markets with matching frictions and the effects of frictions on capital taxes. More importantly, imperfect labor markets with unemployment in tax competition models deserve more attention from researchers, regardless of whether unemployment occurs due to labor unions or frictions or any other institutional settings.

\section{Appendix}

\section{Pareto-efficient tax}

The planner maximizes $W=U_{i}+\delta\left[U_{j}-\underline{u}_{j}\right]$. With symmetric jurisdictions, the FOC with respect to $t_{i}$ reads

19 Accessed at https://news.gallup.com/poll/1675/most-important-problem.aspx on November 5, 2019. 


$$
\begin{aligned}
\frac{d W}{d t_{i}}= & \frac{\partial U_{i}}{\partial t_{i}}+\delta \frac{\partial U_{j}}{\partial t_{i}} \\
= & v_{i}^{\prime} \theta_{i} k_{i}+(1-\delta)\left[v_{i}^{\prime} \hat{t}_{i}\left(k_{i} \frac{\partial \theta_{i}}{\partial t_{i}}+\theta_{i} \frac{\partial k_{i}}{\partial t_{i}}\right)+\mu_{i} u_{i e}^{\prime}\left(-k_{i} f_{i}^{\prime \prime}\right) \frac{\partial k_{i}}{\partial t_{i}}+\mu_{i}^{\prime}\left(u_{i e}-u_{i u}\right) \frac{\partial k_{i}}{\partial t_{i}}\right] \\
& +(1+\delta)\left[\mu_{i} u_{i e}^{\prime}+\left(1-\mu_{i}\right) u_{i u}^{\prime}\right] \frac{\partial \rho}{\partial t_{i}} \overline{K_{i}}=0
\end{aligned}
$$

where the equality uses (23). Substituting $v_{i}^{\prime} \theta_{i} k_{i}$ from (37) into (20) gives

$$
\begin{aligned}
& \left.\frac{\partial U_{i}}{\partial t_{i}}\right|_{t_{i}=\hat{t}_{i}}=\delta\left\{v_{i}^{\prime} \hat{t}_{i}\left(k_{i} \frac{\partial \theta_{i}}{\partial t_{i}}+\theta_{i} \frac{\partial k_{i}}{\partial t_{i}}\right)\right. \\
& \left.+\mu_{i} u_{i e}^{\prime}\left(-k_{i} f_{i}^{\prime \prime}\right) \frac{\partial k_{i}}{\partial t_{i}}+\mu_{i}^{\prime}\left(u_{i e}-u_{i u}\right) \frac{\partial \theta_{i}}{\partial t_{i}}-\left[\mu_{i} u_{i e}^{\prime}+\left(1-\mu_{i}\right) u_{i u}^{\prime}\right] \frac{\partial \rho}{\partial t_{i}} \bar{K}_{i}\right\} \\
& \quad=\delta\left\{v_{i}^{\prime} \hat{t}_{i}\left(k_{i} \frac{\partial \theta_{i}}{\partial t_{i}}+\theta_{i} \frac{\partial k_{i}}{\partial t_{i}}\right)\right. \\
& \left.+\mu_{i} u_{i e}^{\prime}\left(-k_{i} f_{i}^{\prime \prime}\right) \frac{\partial k_{i}}{\partial t_{i}}+\mu_{i}^{\prime}\left(u_{i e}-u_{i u}\right) \frac{\partial \theta_{i}}{\partial t_{i}}-v_{i}^{\prime}\left(-\frac{1}{2}\right) \theta_{i} k_{i}\right\}
\end{aligned}
$$

where the equality uses (24), (26) and $\bar{K}_{i}=\theta_{i} k_{i}$. The second line of (38) is identical to the second term of (31) due to (26) and (30), so (38) is identical to (31), except that $\delta$ is multiplied.

\section{Example: the sign of (31) and the relationship between $t^{*}$ and $\hat{t}$}

Given symmetric jurisdictions, jurisdictional subscripts are omitted unless necessary. Using the expressions of $\partial \theta_{i} / \partial t_{i}$ and $\partial k_{i} / \partial t_{i}$ in (12),

$$
k_{i} \frac{\partial \theta_{i}}{\partial t_{i}}+\theta_{i} \frac{\partial k_{i}}{\partial t_{i}}=\frac{\theta A_{\theta}-k A_{k}}{2\left(A_{\theta} \eta f^{\prime \prime}-A_{k} \eta^{\prime} f^{\prime}\right)}<0 .
$$

Three variables, $(\hat{t}, k, \theta)$, are determined by FOC (26) for the efficient tax rate $\hat{t}$, labor market equilibrium condition (9), and capital market equilibrium condition (10),

$$
\begin{gathered}
1=\mu u_{e}^{\prime}+(1-\mu) u_{u}^{\prime}, \\
A=\left(1-\epsilon_{i}\right)\left(u_{e}-u_{u}\right)-\epsilon u_{e}^{\prime} k_{i} f_{i}^{\prime}=0, \\
k \theta=\bar{K},
\end{gathered}
$$

where (40) uses $v(z)=z$ and $v^{\prime}(z)=1$. Despite the simple example, it is not possible to find the closed-firm solutions for $(\hat{t}, k, \theta)$, and numerical solutions will be considered below. However, (40) can be solved for $\rho$ and $\hat{t}$ in terms of $k$ and $\theta$. In particular, $w=f-k f^{\prime}=k^{2}$, so (40) becomes 


$$
1=\frac{\theta}{1+\theta}\left[\beta-2 k^{2}-2 \rho \bar{K}\right]+\frac{1}{1+\theta}[\beta-2 \rho \bar{K}] \Longrightarrow \rho=\frac{\beta-1}{2 \bar{K}}-\frac{k^{2} \theta}{\bar{K}(1+\theta)}
$$

Since

$$
\rho=\eta f^{\prime}-t=\frac{\alpha-2 k}{1+\theta}-t,
$$

the last two equations can determine $\hat{t}$, so that

$$
\hat{t}=\frac{\alpha-2 k}{1+\theta}-\frac{\beta-1}{2 \bar{K}}+\frac{k^{2} \theta}{\bar{K}(1+\theta)} .
$$

Using the expression of $\rho$ in (43),

$$
\begin{aligned}
& u_{e}-u_{u}=\beta y_{e}-y_{e}^{2}-\left(\beta y_{u}-y_{u}^{2}\right)=\left(y_{e}-y_{u}\right)\left[\beta-\left(y_{e}+y_{u}\right)\right] \\
& =k^{2}\left[\beta-k^{2}-2 \rho \bar{K}\right]=k^{2}\left[1+\frac{k^{2}(1-\theta)}{1+\theta}\right]>0, \\
& u_{e}^{\prime}=\beta-2 k^{2}-2 \rho \bar{K}=1-\frac{2 k^{2}}{1+\theta}>0, \\
& u_{u}^{\prime}=\beta-2 \rho \bar{K}=1+\frac{2 k^{2}}{1+\theta}>0 .
\end{aligned}
$$

Using (45), along with $u_{2}^{\prime \prime}=-2$ and $f^{\prime \prime}=-2$,

$$
\begin{aligned}
A_{k}= & {\left[(1-\epsilon) u_{e}^{\prime}-\epsilon u_{e}^{\prime \prime} k f^{\prime}\right]\left(-k f^{\prime \prime}\right)-\epsilon u_{e}^{\prime}\left(f^{\prime}+k f^{\prime \prime}\right) } \\
= & \frac{1}{1+\theta}\left[2 k+4 k \theta-4 k^{3}-\theta \alpha+\frac{\theta(\alpha-2 k)\left(6 k^{2}+4 k^{2} \theta\right)}{1+\theta}\right]>0, \\
A_{\theta}= & -\epsilon^{\prime}\left[u_{e}-u_{u}+u_{e}^{\prime} k f^{\prime}\right]=-\frac{1}{1+\theta}\left(\alpha k-2 k^{2}\right)\left(1-\frac{2 k^{2}}{1+\theta}\right)<0 . \\
& \theta A_{\theta}-k A_{k}=-2 k^{2}+\frac{4 k^{3}}{1+\theta}[k-\theta(\alpha-2 k)]<0, \\
& 2\left(A_{\theta} \eta f^{\prime \prime}-A_{k} \eta^{\prime} f^{\prime}\right)=\frac{2(\alpha-2 k)}{(1+\theta)^{3}}\left[4 k+6 k \theta-8 k^{3}-\alpha \theta+\frac{\theta(\alpha-2 k)\left(6 k^{2}+4 k^{2} \theta\right)}{1+\theta}\right]>0 .
\end{aligned}
$$

Substituting (39) and (45)-(46) into (31), the sign of (31) is identical to that of

$$
\begin{aligned}
& \left.\frac{\partial U_{i}}{\partial t_{i}}\right|_{t_{i}=\hat{t}_{i}}=\hat{t}\left(k_{i} \frac{\partial \theta_{i}}{\partial t_{i}}+\theta_{i} \frac{\partial k_{i}}{\partial t_{i}}\right)+\frac{1}{2} \theta k(1-\mu)\left(u_{u}^{\prime}-u_{e}^{\prime}\right) \\
& \cong \Omega(\beta) \equiv\left[\frac{\alpha-2 k}{1+\theta}-\frac{\beta-1}{2 \bar{K}}+\frac{k^{2} \theta}{\bar{K}(1+\theta)}\right]\left[-2 k^{2}+\frac{4 k^{3}}{1+\theta}(k-\theta(\alpha-2 k))\right] \\
& +\frac{4 k^{3} \theta(\alpha-2 k)}{(1+\theta)^{5}}\left[4 k+6 k \theta-8 k^{3}-\alpha \theta+\frac{\theta(\alpha-2 k)\left(6 k^{2}+4 k^{2} \theta\right)}{1+\theta}\right] .
\end{aligned}
$$

As the expression inside the second pair of square brackets is $\theta A_{\theta}-k A_{k}<0$, 
Table 1 Simulation results on $\Omega(\beta)$ with $\theta<1$

\begin{tabular}{rrrll}
\hline$\alpha$ & $\bar{K}$ & $k$ & $\theta$ & $\Omega(\beta)$ \\
\hline 100 & 10 & 32.18 & 0.31 & $-8.50309 \mathrm{E}+12$ \\
100 & 8 & 29.78 & 0.27 & $-4.92644 \mathrm{E}+12$ \\
100 & 6 & 26.80 & 0.22 & $-2.30203 \mathrm{E}+12$ \\
100 & 4 & 22.93 & 0.17 & $-7.23985 \mathrm{E}+11$ \\
100 & 2 & 17.24 & 0.12 & -82912439235 \\
50 & 10 & 20.02 & 0.49 & $-1.39591 \mathrm{E}+11$ \\
50 & 8 & 18.74 & 0.43 & -93246512421 \\
50 & 6 & 17.11 & 0.35 & -51541220897 \\
50 & 4 & 14.90 & 0.27 & -19802657720 \\
50 & 2 & 11.48 & 0.17 & -2953177816 \\
20 & 5 & 8.55 & 0.58 & -137037376.3 \\
20 & 4 & 8.04 & 0.50 & -97327283.89 \\
20 & 3 & 7.38 & 0.41 & -57807113.26 \\
20 & 2 & 6.48 & 0.31 & -24477956.67 \\
20 & 1 & 5.06 & 0.20 & -4219804.551 \\
\hline
\end{tabular}

$$
\Omega^{\prime}(\beta)>0 .
$$

The planner chooses the efficient tax $\hat{t}$ but cannot control the incentive to invest in capital, and $\rho$ must be nonnegative. In addition, to provide the public good $z$, the capital tax must be nonnegative. These restriction, along with (43) and (44), imply

$$
\underline{\beta} \equiv \frac{2 k^{2} \theta}{1+\theta}+1<\beta<\bar{\beta} \equiv \frac{2(\alpha-2 k) \bar{K}+2 k^{2} \theta}{1+\theta}+1 .
$$

Since the expression inside the first pair of square brackets of $\Omega$ in (47) is $\hat{t}$ and is zero at $\bar{\beta}$, and since the expression inside the last pair of square brackets of $\Omega$ in (47) is $2\left(A_{\theta} \eta f^{\prime \prime}-A_{k} \eta^{\prime} f^{\prime}\right)>0$,

$$
\lim _{\beta \rightarrow \bar{\beta}} \Omega(\beta)>0 .
$$

At $\beta$, the expression inside the first pair of square brackets of $\Omega$ in (47), $\hat{t}$, becomes $\frac{\alpha-2 k}{1+\theta}$, and the sign of $\Omega(\beta)$ cannot be determined, so

$$
\lim _{\beta \rightarrow \underline{\beta}} \Omega(\beta)>\text { or }<0 .
$$

Thus, (48) through (51) imply that (i) $\lim _{\beta \rightarrow \beta} \Omega(\beta)>0$, and $\Omega(\beta)>0$ and $t^{*}>\hat{t}$ for all $\beta \in(\underline{\beta}, \bar{\beta})$, or (ii) $\lim _{\beta \rightarrow \underline{\beta}} \Omega(\beta)<0$, and there exists $\beta^{*} \in(\underline{\beta}, \bar{\beta})$ such that $\Omega(\beta)<(=,>) 0$ and $t^{*}<(=,>) \hat{t}$ for $\beta<(=,>) \beta^{*}$.

To find if $\Omega(\beta)>0$ or $<0$, (41) and (42), along with (45), are first solved for $k$ and $\theta$ as functions of $(\alpha, \bar{K})$. Using $k$ and $\theta$, simulation results in Table 1 show that 
Table 2 Simulation results on $\Omega(\beta)$ with $\theta \geq 1$

\begin{tabular}{lrlll}
\hline$\alpha$ & $\bar{K}$ & $k$ & $\theta$ & $\Omega(\underline{\beta})$ \\
\hline 100 & 10 & 1.8 & 5.56 & -58435.59217 \\
100 & 8 & 1.69 & 4.73 & -55883.74382 \\
100 & 6 & 1.55 & 3.87 & -50284.99461 \\
100 & 4 & 1.39 & 2.88 & -44951.4637 \\
100 & 2 & 1.16 & 1.72 & -33271.96519 \\
100 & 1 & 1 & 1 & -23289.75 \\
50 & 10 & 1.79 & 5.59 & -13614.12033 \\
50 & 8 & 1.68 & 4.76 & -13028.78199 \\
50 & 6 & 1.55 & 3.87 & -12184.82612 \\
50 & 4 & 1.38 & 2.90 & -10485.55939 \\
50 & 2 & 1.16 & 1.72 & -8131.202027 \\
50 & 1 & 0.99 & 1.01 & -5479.714772 \\
20 & 5 & 1.45 & 3.45 & -1538.824586 \\
20 & 4 & 1.37 & 2.92 & -1478.146214 \\
20 & 3 & 1.27 & 2.36 & -1345.211636 \\
20 & 2 & 1.14 & 1.75 & -1104.312752 \\
20 & 1 & 0.98 & 1.02 & -778.941613 \\
\hline
\end{tabular}

$\Omega(\beta)<0$ for all parameter values, so case (ii) applies. Table 1 assumes $\theta<1$ (and hence $k>\bar{K}$ ), an empirically plausible case (Hall 2005). However, Table 2 presents the simulation results with $\theta \geq 1$ (and $k \leq \bar{K}$ ) for the sake of completeness, and the results again show that $\Omega(\beta)<0$ for all parameter values, and case (ii) applies.

\section{Proof of (34)}

The sign of $\partial A_{i} / \partial H_{i}$ coincides with that of

$$
\left(1-\epsilon_{i}\right)\left(u_{i u}^{\prime}-u_{i e}^{\prime}\right)+\epsilon_{i} u_{i e}^{\prime \prime} k_{i} f_{i}^{\prime}
$$

in (33). Using (9), (52) can be rewritten as

$$
\left(1-\epsilon_{i}\right)\left[\left(u_{i u}^{\prime}-u_{i e}^{\prime}\right)+\left(u_{i e}-u_{i u}\right) \frac{u_{i e}^{\prime \prime}}{u_{i e}^{\prime}}\right] .
$$

Letting $y_{i e}=f_{i}-k_{i} f_{i}^{\prime}+\rho \bar{K}_{i}-H_{i}$ and $y_{i u}=y_{i e}-\triangle_{i}$ with $\triangle_{i} \equiv f_{i}-k_{i} f_{i}^{\prime}>0$, $u_{i e}=u\left(y_{i e}\right)$ and $u_{i u}=u\left(y_{i e}-\triangle_{i}\right)$. (53) can then be rewritten as a function of $\triangle_{i}$, called $Q\left(\triangle_{i}\right) \cdot Q\left(\triangle_{i}\right)$ has two properties. First, $\lim _{\triangle_{i} \rightarrow 0} Q\left(\triangle_{i}\right)=0$, as $u_{i e}=u_{i u}$ and $u_{i e}^{\prime}=u_{i u}^{\prime}$. Second,

$$
Q^{\prime}\left(\triangle_{i}\right)=-\left(1-\epsilon_{i}\right)\left[u_{i u}^{\prime \prime}-u_{i u}^{\prime} \frac{u_{i e}^{\prime \prime}}{u_{i e}^{\prime}}\right]=-\left(1-\epsilon_{i}\right) u_{i u}^{\prime}\left[C_{i e}-C_{i u}\right]
$$


where $C_{i j} \equiv-u_{i j}^{\prime \prime} / u_{i j}^{\prime}, j=e, u$ denotes the coefficient of absolute risk aversion. DARA (CARA, IARA) implies $C_{i e}<(=,>) C_{i u}$ and hence $Q^{\prime}\left(\triangle_{i}\right)>(=,<) 0$. These two properties of $Q\left(\triangle_{i}\right)$ establish (34).

\section{References}

Acemoglu, D. (1996). A microfoundation for social increasing returns in human capital accumulation. Quarterly Journal of Economics, 111, 779-804.

Acemoglu, D., \& Shimer, R. (1999). Efficient unemployment insurance. Journal of Political Economy, 107, 893-928.

Acemoglu, D., \& Shimer, R. (2000). Wage and technology dispersion. Review of Economic Studies, 67, 585-607.

Aronsson, T., \& Wehke, S. (2008). Public goods, unemployment and policy coordination. Regional Science and Urban Economics, 38(3), 285-298.

Attanasio, O., Kugler, A., \& Meghir, C. (2011). Subsidizing vocational training for disadvantaged youth in Colombia: Evidence from a randomized trial. American Economic Journal: Applied Economics, $3(3), 188-220$.

Bartik, T. J. (2017). A new panel database on business incentives for economic development offered by state and local governments in the United States. W. E. Upjohn Institute report, Prepared for the Pew Charitable Trusts.

Baskaran, T., and Lopes da Fonseca, M. (2013). The economics and empirics of tax competition: A survey. CEGE Center for European, Governance and Economic Development Research Discussion Paper, (163).

Bastian, J. (2020). The rise of working mothers and the 1975 earned income tax credit. American Economic Journal: Economic Policy, 12(3), 44-75.

Boadway, R., Cuff, K., \& Marceau, N. (2002). Inter-Jurisdictional Competition for Firms. International Economic Review, 43(3), 761-782.

Boadway, R., Cuff, K., \& Marceau, N. (2004). Agglomeration effects and the competition for firms. International Tax and Public Finance, 11(5), 623-645.

Braulke, M., \& Corneo, G. (2004). Capital taxation may survive in open economies. Annals of Economics and Finance, 5, 237-244.

Brueckner, J., 2000, A Tiebout/tax-competition model, Journal of Public Economics, 77, 285-306.

Dalby, D., \& Scott, M. (2005). "Ireland, Accused of giving tax breaks to multinational, plans an even lower rate." New York Times, October 13, 2015. [accessed at https://www.nytimes.com/2015/10/14/ business/international/ireland-tax-rate-breaks.html on Mrch 12, 2018].

Daruich, D., \& Fernández, R. (2020). Universal basic income: A dynamic assessment (No. w27351). National Bureau of Economic Research.

Diamond, P. (1982). Wage determination and efficiency in search equilibrium. Review of Economic Studies, 49(2), 217-227.

Diamond, P. (2011). Unemployment, vacancies, wages. American Economic Review, 101(4), 1045-1072.

Eichner, T., \& Upmann, T. (2012). Labor markets and capital tax competition. International Tax and Public Finance, 19(2), 203-215.

Eichner, T., \& Upmann, T. (2014). The (Im) possibility of overprovision of public goods in interjurisdictional tax competition. FinanzArchiv: Public Finance Analysis, 70(2): 218-248.

Exbrayat, N., Gaigne, C., \& Riou, S. (2012). The effects of labour unions on international capital tax competition. Canadian Journal of Economics/Revue canadienne d'économique, 45(4), 1480-1503.

Fuest, C., Huber, B., \& Mintz, J. (2005). Capital mobility and tax competition: A survey. Foundations and Trends in Microeconomics, 1(1), 1-62.

Gautier, P., Muller, P., van der Klaauw, B., Rosholm, M., \& Svarer, M. (2018). Estimating equilibrium effects of job search assistance. Journal of Labor Economics, 36(4), 1073-1125.

Graversen, B. K., \& Van Ours, J. C. (2008). How to help unemployed find jobs quickly: Experimental evidence from a mandatory activation program. Journal of Public economics, 92(10-11), 2020-2035. 
Gurria, A. (2014). Taxation and competition policy. Remarks by Angel Gurría, OECD Secretary-General in Brussels, France, February 11, 2014. [accessed at http://www.oecd.org/competition/taxation-andcompetition-policy.htm on February 25, 2019].

Hall, R. E. (2005). Employment fluctuations with equilibrium wage stickiness. American Economic Review, 95, 50-65.

Hungerbühler, M., \& Ypersele, T. V. (2014). Tax Competition in Imperfect Labor Markets. Annals of Economics and Statistics/Annales d'Économie et de Statistique, (113/114), 99-120.

Keen, M., \& Konrad, K. A. (2013). The theory of international tax competition and coordination. In: Handbook of public economics (Vol. 5, pp. 257-328). Elsevier, Amsterdam

Karmakar, K., \& Martinez-Vazquez, J. (2014). Fiscal competition versus fiscal harmonization: A review of the arguments (No. paper1431). International Center for Public Policy, Andrew Young School of Policy Studies, Georgia State University.

Lee, K. (1997). Tax competition with imperfectly mobile capital. Journal of Urban Economics, 42(2), $222-242$.

Lee, K. (2003). Factor ownership and governmental strategic interaction. Journal of Public Economic Theory, 5(2), 345-361.

Lee, K. (2012). Why is mobile capital taxed?. Journal of Economics, 107(2), 157-181.

Leite-Monteiro, M., Marchand, M., \& Pestieau, P. (2003). Employment subsidy with capital mobility. Journal of Public Economic Theory, 5(2), 327-344.

Lejour, A. M., \& Verbon, H. A. (1996). Capital mobility, wage bargaining, and social insurance policies in an economic union. International Tax and Public Finance, 3(4), 495-513.

Livengood, C. (2018). "Grand Rapids offered up to $\$ \$ 2$ billion in tax incentives for Amazon HQ2." Crain's Detroit Business, March 7, 2018 [accessed at http://www.crainsdetroit.com/article/20180 307/ news/654676/grand-rapids-offered-up-to-2-billion-in-tax-incentives-for-amazon-hq2 on March $12,2018]$.

Lorz, O., \& Stähler, F. (2001). Who is afraid of capital mobility? on taxation of labor income and the level of public services in an open economy. Journal of Economics, 74(1), 79-101.

Lozachmeur, J. M. (2003). Fiscal competition, labor mobility, and unemployment. FinanzArchiv: Public Finance Analysis, 59(2): 212-226.

McCall, J. J. (1970). Economics of information and job search. Quarterly Journal of Economics, 84: 113-126.

McKenzie, D. (2017). How effective are active labor market policies in developing countries? a critical review of recent evidence. The World Bank Research Observer, 32(2), 127-154.

Meyer, B. D., \& Rosenbaum, D. T. (2001). Welfare, the earned income tax credit, and the labor supply of single mothers. The quarterly journal of economics, 116(3), 1063-1114.

Moen, E. R. (1997). Competitive search equilibrium. Journal of Political Economy, 105(2), 385-411.

Moriconi, S., \& Sato, Y. (2009). International commodity taxation in the presence of unemployment. Journal of Public Economics, 93(7-8), 939-949.

Mortensen, D. T. (1982). The matching process as a noncooperative bargaining game. In: The economics of information and uncertainty (pp. 233-258). University of Chicago Press, Chicago.

Mortensen, D. T., \& Pissarides, C. A. (1994). Job creation and job destruction in the theory of unemployment. Review of Economic Studies, 61(3), 397-415.

Ogawa, H., Sato, Y., \& Tamai, T. (2006). A note on unemployment and capital tax competition. Journal of Urban Economics, 60(2), 350-356.

Organization for Economic Cooperation and Development. (1998). Harmful tax competition: An emerging global issue. Paris: OECD.

Organization for Economic Cooperation and Development. (2000). Towards global tax co-operation: Progress in identifying and eliminating harmful tax practices. Paris: OECD.

Peralta, S., \& Van Ypersele, T. (2006). Coordination of capital taxation among asymmetric countries. Regional Science and Urban Economics, 36(6), 708-726.

Pissarides, C. A. (2000). Equilibrium unemployment theory. MIT press, Cambridge.

Richter, W. F., \& Schneider, K. (2001). Taxing mobile capital with labor market imperfections. International Tax and Public Finance, 8(3), 245-262.

Rogerson, R., Shimer, R., \& Wright, R. (2005). Search-theoretic models of the labor market: A survey. Journal of Economic Literature, 43(4), 959-988.

Sato, Y. (2009). Capital tax competition and search unemployment. Papers in Regional Science, 88(4), 749-764. 
Shimer, R. (2005). The cyclical behavior of equilibrium unemployment and vacancies. American Economic Review, 95(1), 25-49.

Sørensen, P. B. (2004). International tax coordination: regionalism versus globalism. Journal of Public Economics, 88(6), 1187-1214.

Stevens, M., Grullón Paz, I. (2020). Andrew Yang's 1\$1,000-a-month idea may have seemed absurd before. Not Now. New York Times. March 18, 2020 [accessed at https://www.nytim es.com/2020/03/18/us/politics/universal-basic-income-andrew-yang.html on August 15,2020].

Stevenson, A., \& Ewing, J. (2017). "U.S. Tax bill may inspire cuts globally, while fueling trade tensions." New York Times, December 22, 2017 [accessed at https://www.nytimes.com/2017/12/22/ business/ tax-bill-global-profits.html?rref=collection on March 12, 2018].

Story, L. (2012). “As companies seek tax deals, governments pay high price.” New York Times, December $1,2012$.

Swanson, E. T. (2020). Implications of Labor Market Frictions for Risk Aversion and Risk Premia. American Economic Journal: Macroeconomics, 12(2), 194-240.

Thomas, K. (2011). Investment incentives and the global competition for capital. New York: Palgrove-MacMillan.

Wehke, S. (2008). Fighting tax competition in the presence of unemployment: Complete versus partial tax coordination. FinanzArchiv: Public Finance Analysis, 64(1): 33-62.

Wildasin, D. E. (1989). Interjurisdictional capital mobility: Fiscal externality and a corrective subsidy. Journal of Urban Economics, 25, 193-212.

Wildasin, D. E. (2003). Fiscal competition in space and time. Journal of Public Economics, 87(11), 2571-2588.

Wilson, J. D. (1986). A theory of interregional tax competition. Journal of urban Economics, 19(3), 296-315.

Wildasin, D. E., \& Wilson, J. D. (1998). Risky local tax bases: Risk-pooling vs. rent-capture. Journal of Public Economics, 69(2), 229-247.

Zodrow, G. and Mieszkowski, P. (1986). Pigou, Tiebout property taxation, and the underprovision of local public goods, Journal of Urban Economics 19, 356-370.

Publisher's Note Springer Nature remains neutral with regard to jurisdictional claims in published maps and institutional affiliations. 